Board of Governors of the Federal Reserve System

International Finance Discussion Papers

Number 906

November 2007

The Transmission of Domestic Shocks in the Open Economy

Christopher J. Erceg

Christopher Gust

David López-Salido

NOTE: International Finance Discussion Papers are preliminary materials circulated to stimulate discussion and critical comment. References in publications to International Finance Discussion Papers (other than an acknowledgement that the writer has had access to unpublished material) should be cleared with the author or authors. Recent IFDPs are available on the Web at www.federalreserve.gov/pubs/ifdp/. This paper can be downloaded without charge from Social Science Research Network electronic library at http://www.ssrn.com/. 


\title{
The Transmission of Domestic Shocks in Open Economies
}

\author{
Christopher Erceg* \\ Federal Reserve Board \\ Christopher Gust \\ Federal Reserve Board \\ David López-Salido \\ Federal Reserve Board and CEPR
}

\begin{abstract}
November 2007
Abstract: This paper uses an open economy DSGE model to explore how trade openness affects the transmission of domestic shocks. For some calibrations, closed and open economies appear dramatically different, reminiscent of the implications of Mundell-Fleming style models. However, we argue such stark differences hinge on calibrations that impose an implausibly high trade price elasticity and Frisch elasticity of labor supply. Overall, our results suggest that the main effects of openness are on the composition of expenditure, and on the wedge between consumer and domestic prices, rather than on the response of aggregate output and domestic prices.
\end{abstract}

JEL Classification: F41, F47, E52

Keywords: open economy Phillips Curve, variable markups, imported intermediate inputs.

Acknowledgements: We thank Malin Adolfson (our discussant), Jordi Galí, Mark Gertler, Steve Kamin, Donald Kohn, Andrew Levin, and John Taylor for helpful comments and suggestions, and seminar participants at the Federal Reserve Board, and at the June 2007 NBER Conference "International Dimensions of Monetary Policy." We also thank Hilary Croke for excellent research assistance. The views expressed in this paper are solely the responsibility of the authors and should not be interpreted as reflecting the views of the Board of Governors of the Federal Reserve System or of any other person associated with the Federal Reserve System.

* Corresponding author: 20th and C Streets NW, Washington, DC 20051 USA; phone: 202-452-2575; fax: 202-872-4926. Email addresses: christopher.erceg@frb.gov, christopher.gust@frb.gov, david.lopez-salido@frb.gov. 


\section{Introduction}

With the rapid expansion in world trade during the past two decades, policymakers have become increasingly interested in the consequences of greater trade openness for macroeconomic behavior. Considerable attention has focused on how external shocks may play a more prominent role in driving domestic fluctuations as trade linkages grow, and as developing countries such as China exert a progressively larger influence on global energy and commodity prices. Our paper examines a different aspect of globalization that has received less scrutiny in the recent literature. In particular, we investigate whether changes in trade openness are likely to have a substantial impact on the transmission of domestic shocks.

Economists have long recognized that openness could potentially affect the responses of real activity to domestic shocks, including to monetary and fiscal policy. The Mundell (1962) and Fleming (1962) framework showed that fiscal shocks could have dramatically different effects depending on whether an economy was open or closed: in contrast to the stimulative effect of a government spending rise on output in a closed economy, the same shock had no effect on output in an open economy, as real exchange rate appreciation crowded out real net exports.

A longstanding literature has also assessed the implications of openness for the effects of domestic shocks on inflation. Perhaps most obviously, economists drew attention to the potential divergence between domestic prices and consumer prices in an open economy, reflecting the sensitivity of the latter to import prices. But important contributions in the 1970s and early 1980s also analyzed how the behavior of domestic price-setting could be affected by openness. Influential work by Dornbusch (1983) linked the desired markup in a monopolistic competition framework to the real exchange rate, and showed how the markup could be expected to decline in response to real exchange rate appreciation (reflecting increased competitive pressure from abroad). In an NBER conference volume nearly a quarter century ago, Dornbusch and Fischer (1984) used this framework to argue that changes in the slope of the Phillips Curve due to increased trade openness were likely to have substantial 
implications for the transmission of monetary and fiscal policy. Specifically, these authors argued that monetary shocks were likely to cause domestic prices to respond more quickly due to an effective steepening of the Phillips Curve.

In this paper, we use a two country DSGE modeling framework to revisit the question of how changes in trade openness affect the economy's responses to monetary and fiscal shocks, as well as to a representative supply shock. ${ }^{1}$ Our analysis is heavily influenced by several important papers that compare the characteristics of optimal policy rules in closed and open economies by Clarida, Galí, and Gertler (2001), Clarida, Galí, and Gertler (2002), and Galí and Monacelli (2005). ${ }^{2}$ However, the main objective of these papers was to highlight conditions under which the policy problem in closed and open economies was formally similar: under such conditions, policy prescriptions from the closed economy carried over to the open economy with suitable changes in parameters. Our paper differs substantially insofar as its objective is to provide a quantitative assessment of the differences in the transmission channel as the trade openness of the economy varies.

We focus much of our analysis on a simple "workhorse" open economy model that extends Galí and Monacelli (2005) by incorporating nominal wage rigidities and additional shocks. Although our model allows for spillover effects between the two countries, it can be approximated by a system of dynamic equations that parallels the closed economy model of Erceg, Henderson, and Levin (2000) in the special case in which the home country's share of world output becomes arbitrarily small. As in the Erceg, Henderson, and Levin (2000) model, the presence of nominal wage rigidities confronts the policymaker with a tradeoff between stabilizing inflation and the output (or employment) gap. The parsimonious structure of our open economy model makes it easy to identify the economic channels through which openness affects aggregate demand and supply, and hence the tradeoffs confronting

\footnotetext{
${ }^{1}$ Our approach follows the seminal work of Obstfeld and Rogoff (1995) and a large subsequent literature that incorporates nominal rigidities into microfounded open-economy DSGE models. See Lane (2001) for a survey.

2 There is a burgeoning literature examining optimal monetary policy in an open-economy setting. Some notable examples include Benigno and Benigno (2003), Corsetti and Pesenti (2005), and Devereux and Engel (2003).
} 
policymakers. But while distinguishing these channels is useful for heuristic purposes, the differences between the closed and open economies can be attributed to effects on a single composite parameter that affects the behavioral equations in the same way as the intertemporal elasticity of substitution parameter $(\sigma)$ in a closed economy model: i.e., by affecting the interest elasticity of aggregate demand, and the wealth effect on labor supply. ${ }^{3}$ Given that this parameter can be expressed as a weighted average of the intertemporal elasticity of substitution and the trade price elasticity, where the weight on the latter varies directly with openness, it is straightforward to assess how changes in openness affect equilibrium responses under a wide range of calibrations.

Our analysis shows that, in principle, there could be very pronounced divergence in the effects of the domestic shocks on output and domestic inflation as trade openness increases. In particular, with both a very high trade price elasticity and Frisch elasticity of labor supply, the enhanced ability to smooth consumption in the open economy markedly alters the wealth effect of shocks on labor supply, and the slope of the household's MRS schedule (tending to flatten it). These changes can have substantial effects on aggregate supply, and through their effect on marginal costs, on domestic inflation and output. Moreover, on the aggregate demand side, higher openness increases the effective interest-elasticity of the economy, provided that the trade price elasticity is higher than the intertemporal elasticity of substitution in consumption. In the extreme case in which the trade price elasticity becomes infinitely high, our workhorse model in fact implies that government spending shocks have no effect on output.

However, under more empirically plausible values of the trade price elasticity, the structural relations determining domestic inflation are not very sensitive to the parameters determining openness. The interest-sensitivity of aggregate demand, or "slope" of the New Keynesian IS curve, exhibits somewhat more variation with openness, reflecting that the trade price elasticity (of 1-1/2) is much higher than the intertemporal elasticity of substitu-

\footnotetext{
${ }^{3}$ This extends the results of Galí and Monacelli (2005), who also showed that the effects of openness can be summarized in a single composite parameter.
} 
tion of consumption under our benchmark calibration (so that putting a larger weight on the former, as occurs with greater openness, increases the interest-sensitivity of the economy). Overall, although openness does exert some effect on the responses of domestic inflation, output, and real interest rates to the inflation target change, government spending, and technology shocks we consider, the size of the changes seems quite modest given the wide range of variation in the trade share examined (from 0 to 35 percent). The main implications of openness are apparent in the composition of the expenditure response, with exports playing a larger role in a highly open economy, and in the wedge between consumer and domestic prices.

We then proceed to consider several variants of our workhorse model. First, we compare incomplete markets with the complete markets setting, and again conclude that openness exerts fairly small effects unless the trade price elasticity and Frisch elasticity of labor supply are quite high. Second, we consider endogenous capital accumulation, and find that the differences between closed and open economies are even smaller than in our workhorse model, reflecting in part that endogenous capital boosts the interest-rate elasticity of domestic demand. Third, we consider a specification in which imports are used as intermediate goods; for reasonable calibrations of the import share, it seems to have small effects on our results. Fourth, we examine the implications of a framework that allows for both local currency pricing (as in Betts and Devereux (1996) and Devereux and Engel (2002)) and variable desired markups in the spirit of Dornbusch. We find that these mechanisms can amplify differences in the response of domestic inflation as the degree of openness varies. For example, domestic inflation falls by less in response to a positive technology shock in a highly open economy, reflecting that the associated exchange rate depreciation reduces the price competitiveness of imports (which encourages domestic producers to boost their markups). However, large differences in trade openness appear required for these effects to show through quantitatively.

A natural question is whether the alternative specifications suggested above would affect our conclusions if they were incorporated into our model jointly rather than in isolation. We address this question by examining the responses of the SIGMA model. SIGMA is a 
multicountry DSGE model used at the Federal Reserve Board for policy simulations, and is well-suited to address this question insofar as it includes many of the key features of the workhorse model and the variants, as well as various real rigidities designed to improve its empirical performance (e.g., adjustment costs on imports). We consider the responses of the SIGMA model to the same underlying shocks - including to the inflation target, government spending, and technology - and essentially corroborate our main finding that the responses of domestic inflation and output are not particularly sensitive to openness.

This paper is organized as follows. We begin by presenting the simulations of the SIGMA model in Section 2. This approach proves helpful both as a way of highlighting our main results, and for pointing out some restrictive features of the heuristic models discussed in the subsequent sections against the backdrop of this more general model (e.g., the implications of abstracting from capital accumulation in the workhorse model). Section 3 describes the workhorse model, and then assesses how openness affects the equilibrium under both flexible and sticky prices. Section 4 considers several modifications of the workhorse model. Section 5 concludes.

\section{Theoretical and Empirical Motivation}

In this section, we use a two country version of the SIGMA model to illustrate how trade openness affects the propagation of three different domestic shocks, including a reduction in the central bank's target inflation rate, a rise in government spending, and a highly persistent rise in technology. In the case of the shock to the inflation target, we compare the model's implications to historical episodes of disinflation that occurred in the United States, Canada, and the United Kingdom during the early 1980s and early 1990s. Readers who wish to skip ahead to Sections 3 and 4 - in which we fully describe a much simpler workhorse DSGE model and some variants to investigate the same questions - may do so without loss of continuity. 


\section{$2.1 \quad$ SIGMA Simulations}

SIGMA incorporates an array of nominal and real rigidities to help the model yield plausible implications across a broad spectrum of domestic and international shocks. ${ }^{4}$ On the aggregate demand side, it allows for habit persistence in consumption, costs of changing the level of investment, and costs of adjusting trade flows. ${ }^{5}$ Final consumption and investment goods are produced using both domestically-produced goods and imports. International financial markets are incomplete, so that households are restricted to borrowing or lending internationally through the medium of a non-state contingent bond. On the supply side, prices are set in staggered Calvo-style contracts in both the home and foreign market, with exporters setting their price in local currency terms, as in Betts and Devereux (1996) and Devereux and Engel (2002). SIGMA embeds demand curves with non-constant elasticities (NCES) that induce 'strategic complementarity' in price setting (as in Kimball (1995)). In the spirit of Dornbusch (1983), this feature implies that the desired markup varies in response to real exchange rate fluctuations, creating an incentive for firms to charge different prices in home and foreign markets even under fully flexible prices. As shown by Bergin and Feenstra (2001), Gust, Leduc, and Vigfusson (2006), and Gust and Sheets (2006), it can account for low exchange rate passthrough to import prices. Wages are also set in staggered Calvo-style contracts. ${ }^{6}$

Monetary policy is assumed to follow a Taylor rule in which the nominal interest rate responds to the deviation of domestic inflation from the central bank's inflation target and to the output gap. Government purchases are exogenous, have no direct effect on the utility of households, and are financed by lump-sum taxes.

\footnotetext{
${ }^{4}$ An inclusive description of SIGMA is provided by Erceg, Guerrieri, and Gust (2006) for the case in which product demand is characterized by a Dixit-Stiglitz CES aggregator, implying a constant desired markup. Gust and Sheets (2006) extend the model to allow for variable desired markups, as in the version used in this paper, though they abstract from capital accumulation and examine a smaller array of shocks.

${ }^{5}$ Our specification of habit persistence in consumption and adjustment costs on investment follows Smets and Wouters (2003).

${ }^{6}$ Following Christiano, Eichenbaum, and Evans (2005), SIGMA incorporates dynamic indexation of both price and wage contracts, though the latter are indexed to past aggregate wage inflation.
} 
Figure 1 shows the effects of a one percentage point permanent reduction in the home country's inflation target under three different calibrations of trade openness. The solid line shows the effects under our benchmark calibration based on U.S. data, so that the ratio of imports to GDP is 12 percent. The dashed line shows an alternative in which we lower the import share to 1 percent (labeled "nearly closed"), while the dotted line shows a second alternative in which the import share is 35 percent ("high openness"). ${ }^{7}$ The horizontal axis shows quarters that have elapsed following the shock.

The effects of the reduction in the inflation target are qualitatively similar regardless of the degree of openness. The reduction in the inflation target requires policymakers to increase interest rates, causing output to contract and the real exchange rate (not shown) to appreciate. Private absorption falls in response to the higher interest rates, and exports also decline due to the induced appreciation of the real exchange rate. Both domestic and consumer price inflation fall, and roughly converge to their new target level after two years.

Perhaps somewhat remarkably, the responses of key macro aggregates - including output, domestic price inflation, and the real interest rate - show little quantitative variation with different degrees of openness. The sacrifice ratio - which we measure as the sum of (annualized) output gaps in the twenty quarters following the start of the disinflation, divided by the change in the inflation rate of one percentage point - is about 1.1 under each calibration. Aside from the slightly larger initial output decline under the high openness calibration, the main differences in the responses are compositional. For the highly open economy, more of the output contraction is attributable to a fall in real net exports; in addition, given the larger share of imported goods in the consumption basket, there is a greater disparity between the response of consumer price inflation and domestic price inflation.

The similarity in the responses of output, domestic price inflation, and the real interest rate is mainly attributable to two factors. First, the interest-sensitivity of aggregate demand only rises slightly as trade openness increases. Although our benchmark calibration imposes

\footnotetext{
${ }^{7}$ In these experiments, we vary openness by changing the share parameter in the NCES aggregators used to produce consumption and investment from the home and foreign goods.
} 
a rather high long-run trade price elasticity of 1-1/2, providing a strong channel (through the uncovered interest parity condition) for real interest rates to influence exports, private absorption has a comparable interest-sensitivity due to the high responsiveness of investment. This can be garnered from the bottom panels of the figure: exports only contract a bit more sharply than private absorption in response to higher real interest rates. This helps to explain why output only shows a slightly larger contraction under a 35 percent trade share than in the case in which the trade share is only 1 percent of GDP. ${ }^{8}$ The second factor is that desired price markups and real marginal costs do not change significantly with greater openness, so that domestic price inflation responds very similarly across the different calibrations. Overall, these results do not indicate a significant quantitative "steepening" of the Phillips Curve due to greater openness in response to this particular shock. ${ }^{9}$

Interestingly, historical episodes of disinflation in the United States, Canada, and the United Kingdom seem reasonably supportive of the model's implications. Figure 2 shows the evolution of inflation (measured as the annual changes in the GDP deflator) and the output gap (as measured by the OECD) for the United States, Canada, and the United Kingdom for two different periods of disinflation (the early 1980s and early 1990s). As seen in the left column of Figure 2, inflation in both the United States and Canada fell from roughly 10 percent to 4 percent during the disinflations that occurred during the early 1980s, while the output gap expanded (in absolute value) by roughly 6-7 percent in each country. The sacrifice ratio in the United Kingdom was somewhat lower during that episode, as inflation fell by considerably more, while the output gap expanded by a similar amount.

\footnotetext{
${ }^{8}$ Given the presence of adjustment costs on the expenditure components, the interest-sensitivity depends on how persistent an effect the shock has on the real interest rate. For shocks that exert more persistent effects on real interest rates, exports show a relatively higher interest-sensitivity than private domestic demand, and the aggregate interest-sensitivity of the economy rises more substantially with openness. For example, the interest-sensitivity rises more with greater openness under an alternative model calibration that increases the duration of wage and price contracts (since the real interest rate response in that case is more persistent). Similarly, the government spending shock below has a more persistent impact on the real interest rate, with the implication that the economy becomes more interest-sensitive with greater openness.

${ }^{9}$ The limited variation in the desired markup reflects that the real interest rate shows a fairly transient rise, and hence the real exchange rate does not appreciate much. Under an alternative model calibration implying a more persistent rise in real interest rates - derived by assuming longer contract durations - desired markups and hence inflation show more variation with openness.
} 
In the 1990s, the three experiences also were reasonably similar, with Canada perhaps having a somewhat higher sacrifice ratio than the United States, and the United Kingdom a slightly lower sacrifice ratio. Thus, while the evidence is somewhat noisy, the sacrifice ratio does not appear to vary with openness in a systematic way. ${ }^{10}$

Figure 3 shows the effects of an increase in government spending. ${ }^{11}$ From a qualitative perspective, the government spending hike has similar effects on key macroeconomic variables across the alternative calibrations. The expansion in aggregate demand initially raises output and real interest rates. Higher real interest rates and an induced appreciation of the real exchange rate eventually cause output to revert towards baseline due to a crowding out of private domestic demand and real net exports. Domestic inflation rises because of a positive output gap, and because the expansion in the level of output puts additional upward pressure on marginal cost; the latter effect reflects the interplay of diminishing returns and nominal wage rigidity, so that the real wage remains above the level that would prevail under flexible wage adjustment. ${ }^{12}$

Comparing the alternative calibrations, it is evident that higher openness mitigates the rise in output, short-term real interest rates, and inflation. Quite intuitively, a highly open economy can rely on a decline in real net exports to alleviate pressure on domestic resources: under our benchmark calibration, this effect is large enough to imply that the fiscal shock imparts less stimulus to domestic output, and boosts interest rates by less. Nevertheless, the differences in the output responses are not especially pronounced given the wide variation in trade shares examined, and even differences in the response of short-term interest rates are small after a few years (i.e., given the expectations theory holds in our log-linearized model,

\footnotetext{
${ }^{10}$ Ball (1994) reached similar conclusions based on sacrifice ratios for a much larger set of episodes. Our approach differs insofar as we compare sacrifice ratios across countries over similar time periods (rather than pooling all episodes together) as a rough means of controlling for different levels of monetary policy credibility.

${ }^{11}$ Government spending is modelled as an AR(1) process with an autocorrelation coefficient equal to 0.97 .

${ }^{12}$ Thus, even if the monetary rule were aggressive enough to close the output gap, the gap between the real wage and flexible price real wage would put upward pressure on marginal cost and inflation. We provide an extensive discussion of the implications of the "real wage gap" for marginal cost and inflation in Section 3.7 .
} 
longer-term real interest rates show much less divergence). Thus, the more salient differences across calibrations are in the composition of the expenditure response. In a relatively closed economy, falling private absorption (especially investment) bears the burden of adjustment, while a decline in real net exports is the catalyst for adjustment in a highly open economy.

The responses of domestic price inflation exhibit fairly substantial variation with trade openness, with the peak inflation response only about half as large in the highly open economy as in the nearly closed economy. Under a Taylor rule, the output gap (not shown) is smaller in the highly open economy, reflecting the higher interest elasticity of aggregate demand. Moreover, the smaller expansion in the level of output also puts less upward pressure on marginal costs (the latter is relevant because wages are sticky). Finally, given that the fall in import prices has a larger effect on consumer prices when trade openness is high, the responses of consumer price inflation show even more divergence than those of domestic inflation.

Figure 4 shows a persistent increase in the level of technology. ${ }^{13}$ The effects are qualitatively similar across the three calibrations. In each case, output has a hump-shaped response peaking around five or six quarters after the shock, both domestic and consumer price inflation fall on impact, and the real exchange rate depreciates.

The fall in domestic price inflation occurs because wages adjust slowly to their higher post-shock level. Openness tends to mute the decline in domestic price inflation through two channels. First, it reduces the magnitude of the rise in the real wage. This is because the real exchange rate depreciation retards the expansion in consumption as the economy becomes more open, so that the wealth effect on labor supply is smaller. Second, the depreciation of the real exchange rate and consequent rise in import prices induce domestic producers to raise their markup, as they feel less competition from foreign producers. In a more open economy, the pricing decisions of foreign exporters becomes relatively more important to the price decisions of domestic firms; thus, the rise in import prices plays a more noticeable role in moderating the fall in domestic prices.

\footnotetext{
${ }^{13}$ The technology shock is an $\operatorname{AR}(1)$ process with an autocorrelation coefficient equal to 0.97 .
} 
Finally, there are pronounced differences in the composition of the output response as openness increases, with real exports playing a more prominent role, as well as in the degree of divergence between consumer and domestic price inflation. Notably, given that exchange rate depreciation pushes up import prices, consumer prices show much less of a decline in the highly open economy.

\section{The Workhorse Model}

Our workhorse model builds heavily on the small open economy model of Galí and Monacelli (2005), which we extend to a two country setting. Because these countries may differ in population size, but are otherwise isomorphic, our exposition focuses on the "home" country. Each country in effect produces a single domestic output good, though we adopt a standard monopolistically competitive framework to rationalize stickiness in the aggregate price level. Households consume both the domestically-produced good and an imported good. Household preferences are assumed to be of the constant elasticity form, which allows us to analyze the implications of home bias, and a price elasticity of import demand different from unity. Finally, we generalize the Galí and Monacelli (2005) model by incorporating nominal wage rigidities.

\subsection{Households and Wage Setting}

There is a continuum of monopolistically competitive households indexed by $h \in[0,1]$, each of which supplies a differentiated labor service to an intermediate goods-producing sector (the only producers demanding labor services in our framework). It is convenient to assume that a representative labor aggregator (or "employment agency") combines households' labor hours in the same proportions as firms would choose. Thus, the aggregator's demand for each household's labor is equal to the sum of firms' demands. The aggregate labor index $L_{t}$ has the Dixit-Stiglitz form:

$$
L_{t}=\left[\int_{0}^{1}\left(\zeta N_{t}(h)\right)^{\frac{1}{1+\theta_{w}}} d h\right]^{1+\theta_{w}},
$$


where $\theta_{w}>0$ and $N_{t}(h)$ is hours worked by each member of household $h$. The parameter $\zeta$ is the size of a household of type $h$. It determines the size of the home country's population, and effectively the share of world output produced by the home country in the steady state. The aggregator minimizes the cost of producing a given amount of the aggregate labor index, taking each household's wage rate $W_{t}(h)$ as given, and then sells units of the labor index to the production sector at their unit cost $W_{t}$ :

$$
W_{t}=\left[\int_{0}^{1} W_{t}(h)^{\frac{-1}{\theta_{w}}} d h\right]^{-\theta_{w}} .
$$

It is natural to interpret $W_{t}$ as the aggregate wage index. The aggregator's demand for the labor services of a typical member of household $h$ is given by

$$
N_{t}(h)=\left[\frac{W_{t}(h)}{W_{t}}\right]^{-\frac{1+\theta_{w}}{\theta_{w}}} L_{t} / \zeta .
$$

The utility functional of household $h$ is

$$
\mathbb{E}_{t} \sum_{j=0}^{\infty} \beta^{j} \frac{\sigma}{\sigma-1} C_{t+j}(h)^{\frac{\sigma-1}{\sigma}}-\frac{\chi_{0}}{1+\chi} N_{t+j}(h)^{1+\chi},
$$

where $C_{t}(h)$ and $N_{t}(h)$ denote each household's current consumption and hours of labor, respectively (which are assumed to be identical across the household's individual members). The intertemporal elasticity of substitution in consumption, $\sigma$, satisfies $\sigma>0$, and we assume that $0<\beta<1, \chi>0$, and $\chi_{0}>0$.

Household $h$ faces a flow budget constraint in period $t$ which states that combined expenditure on goods and on the net accumulation of financial assets must equal its disposable income:

$$
P_{C t} C_{t}(h)+\int_{s} \xi_{t, t+1} B_{t+1}(h)=B_{t}(h)+\left(1+\tau_{w}\right) W_{t}(h) N_{t}(h)+R_{K t} K+\Gamma_{t}(h)-T_{t}(h) .
$$

(where variables have been expressed in per capita terms). We assume that household $h$ can trade a complete set of contingent claims, with $\xi_{t, t+1}$ denoting the price of an asset that will pay one unit of domestic currency in a particular state of nature at date $t+1$, and $B_{t+1}(h)$ the quantity of claims purchased (for notational simplicity, we have suppressed all of the state 
indices.) Each household purchases the consumption good at a price $P_{C t}$, and earns (per capita) labor income of $\left(1+\tau_{W}\right) W_{t}(h) N_{t}(h)$, where $\tau_{W}$ is an employment subsidy (designed to allow the flexible price equilibrium to be efficient). Each household also has a fixed stock of capital $(K)$ which it leases to firms at the rental rate $R_{K t}$. It receives an aliquot share $\Gamma_{t}(h)$ of the profits of all firms, and pays lump sum taxes, $T_{t}(h)$ to the government. In every period $t$, household $h$ maximizes the utility functional (4) with respect to its consumption and holdings of contingent claims subject to its budget constraint (5), taking bond prices, the rental price of capital, and the price of the consumption bundle as given.

We assume that household wages are determined by Calvo-style staggered contracts subject to wage indexation. In particular, with probability $1-\xi_{w}$, each household is allowed to reoptimize its wage contract. If a household is not allowed to optimize its wage rate, it resets its wage according to $W_{t}(h)=\omega_{t-1} W_{t-1}(h)$, where $\omega_{t}=W_{t} / W_{t-1}$. Household $h$ chooses the value of $W_{t}(h)$ to maximize its utility functional (4), yielding the following first-order condition:

$$
\mathbb{E}_{t} \sum_{j=0}^{\infty} \beta^{j} \xi_{w}^{j}\left\{\frac{\left(1+\tau_{w}\right)}{\left(1+\theta_{w}\right)} \frac{\Lambda_{t+j}}{P_{C t+j}} V_{w t+j} W_{t}(h)-\chi_{0 t+j} N_{t+j}(h)^{\chi}\right\} N_{t+j}(h)=0,
$$

where $\Lambda_{t}$ is the marginal value of a unit of consumption, and $V_{w t+j}=\prod_{h=1}^{j} \omega_{t+h-1}$. The employment subsidy $\tau_{W}$ is chosen to exactly offset the monopolistic distortion $\theta_{W}$, so that the household's marginal rate of substitution would equal the consumption real wage in the absence of nominal wage rigidities.

\subsection{Firms and Price Setting}

Production of Domestic Intermediate Goods. There is a continuum of differentiated intermediate goods (indexed by $i \in[0,1]$ ) in the home country, each of which is produced by a single monopolistically competitive firm. These differentiated goods are combined into a composite home good, $Y_{t}$, according to

$$
Y_{t}=\left[\int_{0}^{1} Y_{t}(i)^{\frac{1}{1+\theta_{p}}} d i\right]^{1+\theta_{p}}
$$


by a representative firm, or "domestic goods aggregator," that is a perfect competitor in both output and input markets. The aggregator's demand for good $i$ is given by:

$$
Y_{t}(i)=\left(\frac{P_{D t}(i)}{P_{D t}}\right)^{-\frac{\left(1+\theta_{p}\right)}{\theta_{p}}} Y_{t}
$$

where $P_{D t}(i)$ is the price of good $i$ and $P_{D t}$ is an aggregate price index given by $P_{D t}=$ $\left[\int_{0}^{1} P_{D t}(i)^{\frac{-1}{\theta_{p}}} d i\right]^{-\theta_{p}}$.

Intermediate good $i$ is produced by a monopolistically competitive firm, whose output $Y_{t}(i)$ is produced according to a Cobb-Douglas production function:

$$
Y_{t}(i)=K_{t}(i)^{\alpha}\left(Z_{t} L_{t}(i)\right)^{1-\alpha}
$$

where $\alpha>0$ and $Z_{t}$ denotes a stationary, country-specific shock to the level of technology. Intermediate goods producers face perfectly competitive factor markets for hiring capital and labor. Thus, each firm chooses $K_{t}(i)$ and $L_{t}(i)$, taking as given both the rental price of capital $R_{K t}$ and the aggregate wage index $W_{t}$. Within a country, both capital and labor are completely mobile; thus, the standard static first-order conditions for cost minimization imply that all firms have identical marginal cost per unit of output:

$$
M C_{t}=\left(\frac{W_{t}}{1-\alpha}\right)^{1-\alpha}\left(\frac{R_{K t}}{\alpha}\right)^{\alpha}
$$

Similar to household wages, the domestic-currency prices of firms are determined according to Calvo-style staggered contracts subject to indexation. In particular, firm $i$ faces a constant probability, $1-\xi_{p}$, of being able to re-optimize its price, $P_{D t}(i)$. If firm $i$ can not re-optimize its price in period $t$, the firm resets its price according to $P_{D t}(i)=\pi_{t-1} P_{D t-1}(i)$ where $\pi_{t}=P_{D t} / P_{D t-1}$. When firm $i$ can re-optimize in period $t$, the firm maximizes

$$
\mathbb{E}_{t} \sum_{j=0}^{\infty} \xi_{p}^{j} \psi_{t, t+j}\left[\left(1+\tau_{p}\right) V_{D t+j} P_{D t}(i) Y_{t+j}(i)-M C_{t+j} Y_{t+j}(i)\right],
$$

taking $\psi_{t, t+j}, M C_{t}, \tau_{p}, V_{D t}$, and its demand schedule as given. Here, $\psi_{t, t+j}$ is the stochastic discount factor, $V_{D t+j}$ is defined as $V_{D t+j}=\prod_{h=1}^{j} \pi_{t+h-1}$, and $\tau_{p}$ is a production subsidy that 
is calibrated to make the flexible price equilibrium efficient. ${ }^{14}$ The first-order condition for setting $P_{D t}(i)$ is:

$$
\mathbb{E}_{t} \sum_{j=0}^{\infty} \psi_{t, t+j} \xi_{p}^{j}\left(\frac{\left(1+\tau_{p}\right) V_{D t+j} P_{D t}(i)}{\left(1+\theta_{p}\right)}-M C_{t+j}\right) Y_{t+j}(i)=0
$$

Production of Consumption Goods. Final consumption goods are produced by a perfectly competitive "consumption good distributor." The representative distributor combines purchases of the domestically-produced composite good, $C_{D t}$ (obtained from the domestic goods distributor), with an imported good, $M_{C t}$, to produce private consumption, $C_{t}$, according to a CES production function:

$$
C_{t}=\left(\left(1-\omega_{c}\right)^{\frac{\rho_{c}}{1+\rho_{c}}} C_{D t}^{\frac{1}{1+\rho_{c}}}+\omega_{c}^{\frac{\rho_{c}}{1+\rho_{c}}} M_{C t}^{\frac{1}{1+\rho_{c}}}\right)^{1+\rho_{c}}
$$

We assume that the form of this CES aggregator mirrors the preferences of households over consumption of domestically-produced goods and imports. Accordingly, the quasi-share parameter $\omega_{c}$ in equation (13) may be interpreted as determining household preferences for foreign relative to domestic goods. In the steady state, $\omega_{c}$ is the share of imports in the household's consumption bundle, so that the import share of the economy is determined as the product of $\omega_{c}$ and the (private) consumption share of GDP.

The distributor sells its final consumption good to households at price $P_{C t}$ and also purchases the home and foreign composite goods at their respective prices, $P_{D t}$ and $P_{M t}$. We assume that producers of the composite domestic and foreign goods practice producer currency pricing. Accordingly, $P_{M t}=e_{t} P_{D t}^{*}$, where $e_{t}$ is the exchange rate expressed as units of domestic currency required to purchase one unit of foreign currency and $P_{D t}^{*}$ is the price of the foreign composite good in the foreign currency (we use an asterisk to denote foreign variables). Profit maximization implies that the demand schedules for the imported and

\footnotetext{
${ }^{14}$ As discussed earlier in the household problem, we defined $\xi_{t, t+j}$ to be the price in period $t$ of a claim that pays one dollar if the specified state occurs in period $t+j$. Thus, the corresponding element of $\psi_{t, t+j}$ equals $\xi_{t, t+j}$ divided by the probability that the specified state will occur.
} 
domestically-produced aggregate goods are given by:

$$
M_{C t}=\omega_{c}\left(\frac{P_{M t}}{P_{C t}}\right)^{\frac{-\left(1+\rho_{c}\right)}{\rho_{c}}} C_{t} \quad \text { and } \quad C_{D t}=\left(1-\omega_{c}\right)\left(\frac{P_{D t}}{P_{C t}}\right)^{\frac{-\left(1+\rho_{c}\right)}{\rho_{c}}} C_{t} .
$$

The zero profit condition in the distribution sector implies:

$$
P_{C t}=\left(\left(1-\omega_{c}\right) P_{D t}^{\frac{1}{1+\rho_{c}}}+\omega_{c} P_{M t}^{\frac{1}{1+\rho_{c}}}\right)^{1+\rho_{c}} .
$$

According to equation (15), in an open economy, the consumer price level depends on both domestic and foreign prices, while if an economy is closed to trade (i.e., $\omega_{c}=0$ ), consumer prices depend only on domestic prices.

\subsection{Monetary and Fiscal Policy}

We assume that the central bank follows an interest rate reaction function:

$$
i_{t}=\gamma_{\pi}\left(\pi_{t}-\pi_{t}^{T}\right)+\gamma_{y}\left(y_{t}-y_{t}^{p o t}\right),
$$

where the variables have been specified as the logarithmic deviation from its steady state value. The nominal interest rate responds to the deviation of domestic price inflation from the central bank's exogenous inflation target, $\pi_{t}^{T}$, and the deviation of output from potential output $\left(y^{p o t}\right)$, where potential output is defined as the economy's level of output in the absence of sticky wages and prices.

As noted above, openness can give rise to important differences between the domestic price level and the consumer price level. We specify a rule that responds to domestic price inflation rather than consumer price inflation in order to minimize differences between an open and closed economy that would simply be attributable to the monetary rule, rather than to differences in the underlying structure of the economy.

The government purchases some of the domestically produced good. Government purchases, $G_{t}$, are assumed to follow an exogenous, stochastic process. The government's budget is balanced every period so that lump sum taxes equal government spending plus the subsidy to firms and households. 


\subsection{Market Clearing}

The home economy's aggregate resource constraint can be written as:

$$
Y_{t}=C_{D t}+G_{t}+\frac{\zeta^{*}}{\zeta} M_{C t}^{*}
$$

where the inclusion of the relative population size $\frac{\zeta^{*}}{\zeta}$ reflects that all variables are expressed in per capita terms, and $M_{C t}^{*}$ denotes the purchases of the domestically-produced good by foreign final consumption producers. Market clearing in the labor and capital markets implies:

$$
K=\int_{0}^{1} K_{t}(i) d i \quad \text { and } \quad L_{t}=\int_{0}^{1} L_{t}(i) d i .
$$

Finally, we assume that the structure of the foreign economy is isomorphic to that of the home country.

\subsection{Benchmark Calibration}

Three key parameters that play a crucial role in influencing our results are the price elasticity for trade, $\eta_{c}=\frac{1+\rho_{c}}{\rho_{c}}$, the intertemporal elasticity of substitution, $\sigma$, and the labor supply elasticity, $\chi$. While we choose benchmark values of these parameters to be consistent with our interpretation of the evidence, it is important to note that there is wide range of values for these parameters used in the literature and thus we also consider alternative calibrations.

For the trade price elasticity, we assume that $\rho_{c}=2$ which implies $\eta_{c}=\frac{1+\rho_{c}}{\rho_{c}}=1.5$. This estimate is towards the higher end of estimates derived using macroeconomic data, which are typically below unity in the short run and near unity in the long run (e.g., Hooper, Johnson, and Marquez (2000)). Nevertheless, estimates of this elasticity following a tariff change are typically much higher, and we consider higher values in alternative calibrations. ${ }^{15}$

We choose the intertemporal elasticity of substitution to be an intermediate value between estimates derived from two separate literatures. In the micro literature, estimates of the coefficient of relative risk aversion, which correspond to the inverse of the intertemporal

\footnotetext{
${ }^{15}$ For a discussion of the macro estimates and estimates after trade liberalizations, see Ruhl (2005).
} 
elasticity of substitution suggest values in the range of $0.2-0.7 .^{16}$ In contrast, the business cycle literature frequently uses log utility over consumption (i.e., $\sigma=1$ ) to be consistent with balanced growth. We set $\sigma=0.5$ as a compromise between these two different perspectives.

The parameter $\chi$ corresponds to the inverse of the (Frisch) wage elasticity of labor supply. A vast amount of evidence from micro-data suggests labor supply elasticities in the range of 0.05-0.3, though the real business cycle literature tends to use much higher values. ${ }^{17}$ We set $\chi=5$ for the benchmark calibration, which is at the upper end of estimates from the micro data.

We choose the remaining parameters of the model as follows. Given that the model is calibrated at a quarterly frequency, our choice of $\beta=0.9925$ implies an annualized real interest rate of 3 percent. The government spending share of output is set to 18 percent, so $g_{y}=0.18$. We set the elasticity of capital in production function, $\alpha=0.35$ and choose $\chi_{0}$ so that hours worked are normalized to unity in steady state. For the price and wage markup parameters, we choose $\theta_{p}=\theta_{w}=0.2$, and set the corresponding subsidies to equivalent values, $\tau_{p}=\tau_{w}=0.2$. We choose $\xi_{p}$ and $\xi_{w}$ to be consistent with four quarter contracts (subject to full indexation). Finally, we set the relative population size of the home economy $\left(\frac{\zeta}{\zeta^{*}}\right)$ to $1 / 3$. This value implies that the home economy corresponds to 25 percent of world output, which is roughly consistent with the U.S. share of world output.

\subsection{The Flexible Price and Wage Equilibrium}

It is useful to begin our analysis by investigating the behavior of a log-linearized version of the workhorse model under the assumption that wages and prices are fully flexible. For heuristic reasons, we conduct this analysis under the assumption that home country is a small enough fraction of world output that any spillovers to the foreign country (in particular, to

\footnotetext{
${ }^{16}$ See, for example, Attanasio and Weber (1995), Attanasio and Weber (1997), or Barsky, Juster, Kimball, and Shapiro (1997).

${ }^{17}$ MacCurdy (1986) obtained a point estimate of 0.15 for the Frisch elasticity of labor supply for men, a finding largely confirmed in the literature (e.g., Altonji (1986), Card (1994), and more recently Pencavel (2002)). For an alternative view, see Mulligan (1998). Finally, there is more uncertainty regarding the labor supply elasticity for females. For this group, Pencavel (1998) obtained a point estimate of 0.21.
} 
interest rates and domestic demand) can be ignored. Insofar as we have verified by model simulations that spillovers from domestic shocks to the foreign sector are small even when the home country constitutes 25 percent of world output (as in our benchmark calibration), examining the model's implications under the assumption of a very small world output share yields considerable insight. Thus, our analysis here closely parallels that of Galí and Monacelli (2005), aside from modest differences arising from our inclusion of a government spending shock, and allowing for diminishing returns to labor. However, while their paper focused on the formal similarity between open and closed economy models, our goal is to explore the quantitative differences that arise as an economy becomes more open, and how these differences depend on underlying structural parameters such as trade price elasticities.

We begin by deriving a relationship between output and the domestic real interest rate, which Galí and Monacelli (2005) and Clarida, Galí, and Gertler (2002) have characterized as an open economy IS curve. Substituting the (log-linearized) production function for final consumption goods (13) into the resource constraint (17), the latter may be expressed:

$$
y_{t}=\left(1-g_{y}\right)\left(c_{t}+\omega_{c}\left(m_{c t}^{*}-m_{c t}\right)\right)+g_{y} g_{t}
$$

where small letters denote the deviations of the logarithms of variables from their corresponding level, and $g_{y}$ is the government share of output. The risk-sharing condition under complete markets can be used to relate private consumption to foreign consumption $c_{t}^{*}$ and to the terms of trade $\tau_{t}$ :

$$
c_{t}=c_{t}^{*}+\sigma\left(1-\omega_{c}\right) \tau_{t}=c_{t}^{*}+\epsilon_{c} \tau_{t}
$$

where the parameter $\epsilon_{c}=\sigma\left(1-\omega_{c}\right)$ denotes the sensitivity of private consumption to the terms of trade. Using the export and import demand functions, the difference between real exports and imports $m_{c t}^{*}-m_{c t}$ may be expressed:

$$
m_{c t}^{*}-m_{c t}=\left(c_{t}^{*}-c_{t}\right)+\left(1+\left(1-\omega_{c}\right)\right) \eta_{c} \tau_{t}=\left(c_{t}^{*}-c_{t}\right)+\epsilon_{n x} \tau_{t}
$$

Thus, real net exports depend on an activity term (rising as foreign consumption expands relative to domestic consumption), and on the terms of trade. Because a one percent deteri- 
oration of the terms of trade raises exports by an amount equal to the export price elasticity of demand $\eta_{c}$, while causing real imports to contract by $\left(1-\omega_{c}\right) \eta_{c}$, the overall relative price sensitivity of net exports is captured by the composite parameter $\epsilon_{n x}=\left(1+\left(1-\omega_{c}\right)\right) \eta_{c}$.

Substituting these expressions into the resource constraint (19) yields:

$$
y_{t}=\left(1-g_{y}\right)\left(\left(1-\omega_{c}\right) \epsilon_{c}+\omega_{c} \epsilon_{n x}\right) \tau_{t}+g_{y} g_{t}+\left(1-g_{y}\right) c_{t}^{*}
$$

or simply:

$$
y_{t}=\left(1-g_{y}\right) \sigma^{o p e n} \tau_{t}+g_{y} g_{t}+\left(1-g_{y}\right) c_{t}^{*}
$$

The parameter $\sigma^{\text {open }}=\left(\left(1-\omega_{c}\right) \epsilon_{c}+\omega_{c} \epsilon_{n x}\right)$ may be interpreted as either the sensitivity of private aggregate demand to the terms of trade, or the (absolute value of) the sensitivity of private aggregate demand to the long-term real rate of interest. The latter follows from the UIP condition:

$$
\tau_{t}=\mathbb{E}_{t} \tau_{t+1}+r_{t}^{*}-r_{t}=\mathbb{E}_{t} \sum_{j=0}^{\infty}\left(r_{t+j}^{*}-r_{t+j}\right)=\left(r_{L t}^{*}-r_{L t}\right)
$$

where the long-term real interest rate $r_{L t}$ is an infinite sum of expected short-term real interest rates $\left(r_{t+j}\right)$. Alternatively, equation (23) can be expressed in terms of the current short-term real interest rate to yield an "open economy IS curve" of the form:

$$
y_{t}=\mathbb{E}_{t} y_{t+1}-\left(1-g_{y}\right) \sigma^{\text {open }}\left(r_{t}-r_{t}^{*}\right)+g_{y}\left(g_{t}-\mathbb{E}_{t} g_{t+1}\right)+\left(1-g_{y}\right)\left(c_{t}^{*}-\mathbb{E}_{t} c_{t+1}^{*}\right)
$$

Based on the foregoing analysis, the interest-sensitivity of private demand $\sigma^{\text {open }}$ can be regarded as a weighted average of the interest-sensitivity of consumption $\epsilon_{c}$, and of real net exports $\epsilon_{n x}$, with the interest-sensitivity of the latter arising from the UIP relation, and depending on the trade price elasticity. With some algebraic manipulation, $\sigma^{\text {open }}$ can be expressed alternatively as a simple weighted average of the underlying structural parameters $\sigma$ (the intertemporal elasticity of substitution in consumption) and $\eta_{c}$ (the price elasticity of both exports and imports):

$$
\sigma^{\text {open }}=\left(1-\omega_{c}\right)^{2} \sigma+\left(1-\left(1-\omega_{c}\right)^{2}\right) \eta_{c}
$$


The quadratic weight $\left(1-\omega_{c}\right)^{2}$ on $\sigma$ reflects both that consumption gets an effective weight of $\left(1-\omega_{c}\right)$ in private demand (as seen from equation 22 ), and that the elasticity of private consumption with respect to the domestic real interest rate $\left(\epsilon_{c}=\sigma\left(1-\omega_{c}\right)\right)$ declines linearly as the share of foreign goods rises in the domestic consumption bundle.

Equation (26) provides confirmation of the intuitively plausible argument that the interest-sensitivity of the economy should rise with openness if the trade price elasticity is high relative to the intertemporal elasticity of substitution in consumption; and conversely, if the trade price elasticity is relatively low. ${ }^{18}$ Formally, the derivative of $\sigma^{\text {open }}$ with respect to $\omega_{c}$ equals $2\left(1-\omega_{c}\right)\left(\eta_{c}-\sigma\right)$, and hence rises if $\eta_{c}>\sigma$. Thus, even if consumption responded very little to the domestic real interest rate - implying a low interest-elasticity of output in a closed economy - output could still be highly interest-sensitive in an open economy if the interest rate changes generated large movements in real exports and imports (through their influence on the the terms of trade).

From a quantitative perspective, the quadratic weights in (26) imply that openness can have very substantial implications for the interest-sensitivity of the economy if there is a significant divergence between the intertemporal elasticity $\sigma$ and the trade price elasticity $\eta_{c}$. This is apparent from Table 1 , which shows how the interest-elasticity of aggregate demand $\sigma^{\text {open }}$ varies with openness for alternative values of $\sigma$ and $\eta_{c}$. For example, using a trade share of $\omega_{c}=.35$, the weight on $\sigma$ in determining the interest-elasticity of private demand is only $0.42\left(=(1-.35)^{2}\right)$. In this case, an open economy with $\sigma=0.5$ and $\eta_{c}=1.5$ - as in our benchmark calibration - implies $\sigma^{\text {open }}=1.1$, or more than double the interestsensitivity of its closed economy counterpart. With an even higher trade price elasticity of 6 , $\sigma^{\text {open }}$ rises to 3.6 , or more than seven times its closed-economy counterpart. However, changes in the effective interest-sensitivity of aggregate output due to openness are almost

\footnotetext{
${ }^{18}$ In closely related work, Woodford (2007) examines how the monetary transmission mechanism changes with the degree of trade openness in a sticky price model. His model specification imposes a trade price elasticity of unity, and he calibrates the intertemporal elasticity of substitution $\sigma=6$ to proxy for the high interest rate sensitivity of investment. Accordingly, in his calibration, an increase in openness lowers the interest rate sensitivity of the economy.
} 
certainly much smaller than suggested by this latter computation, and probably significantly smaller than implied by our workhorse model which ignores capital. As we show below, to the extent that the disparity between the effective interest-sensitivity of domestic demand and that of real trade narrows in a model with capital accumulation, the interest-sensitivity of the economy shows less variation with openness.

We next turn to the determinants of employment, output, and the real wage (which we will refer to as potential employment, potential output, and the potential real wage in the model with sticky prices). If prices are flexible, firms behave identically in setting prices and hiring factor inputs, so that there is effectively a single representative firm. The labor demand schedule is derived directly from the representative firm's optimality condition for choosing its price, which equates the marginal product of labor to the product real wage (n.b., the product real wage is expressed in units of the domestically produced good). Thus, the (inverse) labor demand schedule may be expressed:

$$
\zeta_{t}^{d}=m p l_{t}=(1-\alpha) z_{t}-\alpha L_{t}
$$

so that the "demand real wage" $\zeta_{t}^{d}$ varies inversely with hours worked. Clearly, both the slope of this schedule and the manner in which it is affected by shocks is identical to a closed economy.

The labor supply schedule is derived from the household's optimality condition equating its marginal rate of substitution between leisure and consumption to the consumption real wage. It is convenient to express labor supply in terms of the product real wage, so that:

$$
\zeta_{t}^{s}=m r s_{t}=\chi L_{t}+\frac{1}{\sigma} c_{t}+\omega_{c} \tau_{t}
$$

where $m r s_{t}$ should be interpreted as the marginal cost of working in terms of the domestically produced good. The terms of trade enters as an additional shift variable. A depreciation of the terms of trade shifts the labor supply schedule inward, because a given product real wage translates into a smaller consumption real wage.

For heuristic purposes, it is useful to derive a labor supply schedule that is expressed exclusively in terms of labor (or output) and endogenous shocks, as is familiar from the 
closed economy analogue, i.e.,

$$
\zeta_{t}^{s, \text { closed }}=\chi L_{t}+\frac{1}{\sigma} \frac{1}{1-g_{y}}\left((1-\alpha)\left(L_{t}+z_{t}\right)-g_{y} g_{c t}\right)
$$

This is easily accomplished by using equation (23) to solve for the terms of trade in terms of output, and then the risk-sharing condition (20) to solve for consumption in terms of output. Finally, using the production function to solve for output in terms of labor, the labor supply function may be expressed:

$$
\zeta_{t}^{s}=\chi L_{t}+\frac{1}{\sigma^{\text {open }}} \frac{1}{1-g_{y}}\left((1-\alpha)\left(L_{t}+z_{t}\right)-g_{y} g_{c t}\right)+\left[\frac{1}{\sigma}-\frac{1}{\sigma^{\text {open }}}\right] c_{D t}^{*}
$$

It is clear from comparing equation (30) with its closed economy analogue (29) that openness can only alter the impact of domestic shocks on the labor market through the parameter $\sigma^{\text {open }}$. This parameter can be interpreted as determining the wealth effect on labor supply in an open economy, influencing both the slope of the labor supply schedule, and how it is affected by shocks. Given the dependence of the "primitive" labor supply schedule (28) on both consumption and the terms of trade, the wealth effect in (30) captures the effects of movements in both variables. From our earlier derivation of the open-economy IS curve, $\sigma^{\text {open }}$ rises relative to the intertemporal elasticity $\sigma$ if the trade price elasticity $\eta_{c}$ exceeds $\sigma$. Intuitively, a relatively high degree of substitutibility between home and foreign goods should enhance opportunities for international risk-sharing, serving to weaken the relationship between consumption and output, and hence the wealth effect on labor supply.

Figure 5 illustrates how openness affects labor market equilibrium in response to a technology shock through changing both the slope of the labor supply schedule, and the extent to which it shifts in response to the shock. The left panel shows the response in a closed economy, while the right panel shows the response in an open economy. The technology shock shifts the labor demand schedule up by one percent in both the closed and open economy (recalling that this schedule is the same in each). In the closed economy, the wealth effect on labor supply is determined by the parameter $\sigma$ (in equation (29)), which is assumed to be less than unity. Accordingly, the wealth effect on labor supply dominates the substitution 
effect. In the new equilibrium at point $\mathrm{B}$, hours worked decline, and the real wage rises. Turning to the open economy case, the structural parameters are assumed to imply a value of $\sigma^{\text {open }}$ in equation (30) that significantly exceeds unity (as would occur with a high value of the trade price elasticity, and high degree of openness). In this case, the open economy MRS schedule shifts inward by much less (i.e., from A to E) than its closed economy counterpart (from $\mathrm{A}$ to $\mathrm{D}$ in the left panel). In addition to reducing the shift in the schedule, the smaller wealth effect implies a flatter MRS schedule. Accordingly, with the substitution effect dominating the wealth effect, labor hours expand, and the real wage rises by less than in the closed economy.

From a quantitative perspective, openness can have sizeable macroeconomic consequences under calibrations of structural parameters that imply a large wedge between $\sigma^{\text {open }}$ and $\sigma$, and that embed a high Frisch elasticity of labor supply $\frac{1}{\chi}$. The Frisch elasticity is relevant because it determines the sensitivity of the MRS slope (of $\left.\chi+\frac{1-\alpha}{\left(1-g_{y}\right) \sigma^{\text {open }}}\right)$. As the Frisch elasticity of labor supply and the trade price elasticity become very large, the labor supply schedule flattens, and also becomes unresponsive to the technology and government spending shocks. Under these limiting conditions, the productivity shock exerts a large effect on output with no impact on the real wage. The government spending shock has no effect on output, employment, or wages, which is reminiscient of the dramatically different effects of fiscal expansion on output in a closed versus open economy that obtain in a traditional Mundell-Fleming style model.

However, although increased openness can have large effects in principle, it has much less dramatic implications for flexible-price employment, output, and the real wage under plausible calibrations. This is apparent from Tables 1 and 2, which show how the responses of these key variables in the flexible price equilibrium vary with openness under a wide range of values of the trade price elasticity and the intertemporal elasticity of substitution in consumption (the superscript "pot" on each variable is used to denote "potential" responses, meaning the responses under flexible prices and wages). Table 1 shows responses under a Frisch elasticity of 0.2 , as in our benchmark calibration, while Table 2 considers a higher 
elasticity of unity. Importantly, for trade price elasticities in the empirically-reasonable neighborhood of 1 to 1.5, and a Frisch elasticity of unity or below, differences between the closed and open economy responses to a technology shock are quite small, and only modestly larger in the case of a government spending shock.

\section{7 $\quad$ Sticky Prices and Wages}

We next turn to analyzing the model's behavior in the presence of nominal wage and price rigidities. We continue to maintain the assumption that the relative share of the home economy in world output is arbitrarily small. In this case, the log-linearized behavioral equations can be expressed in a simple form that is essentially identical to that derived in the closed economy model of Erceg, Henderson, and Levin (2000), aside from allowing for the indexation of wages and prices:

$$
\begin{gathered}
x_{t}=x_{t+1 \mid t}-\sigma^{o p e n}\left(1-g_{y}\right)\left(i_{t}-\pi_{t+1 \mid t}-r_{t}^{p o t}\right) \\
\Delta \pi_{t}=\beta \Delta \pi_{t+1 \mid t}+\kappa_{p}\left(\zeta_{t}-M P L_{t}\right) \\
\Delta \omega_{t}=\beta \Delta \omega_{t+1 \mid t}+\kappa_{w}\left(M R S_{t}-\zeta_{t}\right) \\
M P L_{t}=\zeta_{t}^{p o t}-\lambda_{M P L} x_{L t}=\zeta_{t}^{p o t}-\frac{\lambda_{m p l}}{(1-\alpha)} x_{t} \\
M R S_{t}=\zeta_{t}^{p o t}+\lambda_{m r s} x_{L t}=\zeta_{t}^{p o t}+\frac{\lambda_{m r s}}{(1-\alpha)} x_{t} \\
\zeta_{t}=\zeta_{t-1}+\omega_{t}-\pi_{t}
\end{gathered}
$$

where $x_{t}$ is the output gap (i.e., $\left.y_{t}-y_{t}^{p o t}\right), x_{L t}$ is the employment gap (i.e., $l_{t}-l_{t}^{p o t}$ ), $r_{t}^{p o t}$ is the "potential" (or "natural") rate of interest, $\zeta_{t}^{\text {pot }}$ the potential real wage, and the composite 
parameters are defined by $\kappa_{p}=\frac{\left(1-\xi_{p}\right)\left(1-\beta \xi_{p}\right)}{\xi_{p}}, \kappa_{w}=\frac{\left(1-\xi_{w}\right)\left(1-\beta \xi_{w}\right)}{\xi_{w}\left(1+\chi \frac{1+\theta_{w}}{\theta_{w}}\right)}, \lambda_{m r s}=\chi+\frac{1-\alpha}{\sigma^{\text {open }}\left(1-g_{y}\right)}$, and $\lambda_{m p l}=\alpha$. The potential level of a variable is defined as the value it would assume if prices and wages were fully flexible. The model is completed with the inclusion of the monetary rule given in equation (16).

Equation (31) parsimoniously expresses the open economy IS curve in terms of output and real interest rate gaps. Thus, the output gap depends inversely on the deviation of the real interest rate $\left(i_{t}-\pi_{t+1 \mid t}\right)$ from its potential rate $r_{t}^{\text {pot }}$. The price-setting equation (32) specifies the change in domestic price inflation to depend on the future expected change in inflation and real marginal cost, where the latter is the difference between the real wage and marginal product of labor. The wage-setting equation (33) specifies the change in wage inflation to depend on the future expected change in wage inflation and the difference between the MRS and real wage (both in product terms). The equations determining the MPL (34) and MRS (35) can be specified to depend only on the real wage under flexible prices $\zeta_{t}^{p o t}$, and the employment gap (or equivalently, the output gap, since the latter is proportional). Finally, equation (36) is an identity for the evolution of the product real wage.

The log-linearized representation given by equations (31) - (36) is insightful in helping to assess how openness affects the transmission of domestic shocks under a given policy rule, and also the policymaker's tradeoff frontier under certain commonly specified loss functions. In particular, equations (31) - (36) identify several channels through which openness can affect the economy. It is evident from (31) that openness can influence aggregate demand through affecting both the potential real interest rate $r_{t}^{p o t}$, and the sensitivity of the output gap to a given-sized real interest rate change (this sensitivity is determined by $\sigma^{\text {open }}\left(1-g_{y}\right)$ ). The interest-sensitivity of aggregate demand increases with openness if the trade price elasticity exceeds the intertemporal elasticity of substitution in consumption; conversely, the interestsensitivity decreases if the trade price elasticity is relatively low.

It is apparent that openness influences aggregate supply directly through affecting the sensitivity of the household's MRS to the employment gap, i.e., the parameter $\lambda_{m r s}$ in equation (35). The effects of this slope change on price-setting are most pronounced in the 
special case of fully flexible wages. In this case, equation (35) implies that the real wage can be expressed directly in terms of the potential real wage and employment gap, i.e., $\zeta_{t}=\zeta_{t}^{p o t}+\lambda_{m r s} x_{L t}$. Substituting for the real wage into the price-setting equation (32), and for the MPL using (34), yields an "open economy New Keynesian Phillips Curve" similar to that derived by Clarida, Gali, and Gertler (aside from allowing for indexation):

$$
\Delta \pi_{t}=\beta \Delta \pi_{t+1 \mid t}+\kappa_{p}\left(\left(\lambda_{m p l}+\lambda_{m r s}\right) x_{L t}\right)
$$

Given that $\lambda_{m p l}$ is determined by the capital share - a small number equal to 0.35 under our benchmark calibration - the slope of the Phillips Curve hinges crucially on $\lambda_{m r s}$. Under the conditions discussed previously in which openness markedly affects $\lambda_{m r s}$, it also exerts substantial effects on the Phillips Curve slope. For instance, if openness significantly reduces $\lambda_{m r s}$ - as occurs under a high Frisch elasticity and relatively high trade price elasticity marginal cost and hence price inflation are much less responsive to the output gap in a highly open economy. In the presence of nominal wage rigidities, however, the close linkage between the real wage and employment gap is severed, with the implication that the MRS slope has much less of a direct impact on the transmission of shocks to marginal costs and price inflation. Even so, changes in the MRS slope due to openness can have an important impact on the behavior of wage inflation.

Openness also influences aggregate supply through altering the response of the potential real wage $\zeta_{t}^{\text {pot }}$ : from equations (32) - (35), it is evident that $\zeta_{t}^{\text {pot }}$ affects both price- and wagesetting behavior. Because openness affects $\zeta_{t}^{p o t}$ through altering the MRS slope $\lambda_{m r s}$ as well as the wealth effect of shocks on labor supply (as discussed above, following equation 30), this provides a second, albeit indirect, channel through which the MRS slope affects aggregate supply. Importantly, changes in $\zeta_{t}^{\text {pot }}$ due to openness can in principle have substantial consequences for price-setting. To see this, it is useful to substitute equation (34) into (32) to obtain:

$$
\Delta \pi_{t}=\beta \Delta \pi_{t+1 \mid t}+\kappa_{p}\left(\zeta_{t}-\zeta_{t}^{p o t}+\lambda_{m p l} x_{L t}\right)
$$

Thus, in the presence of sticky nominal wages, price inflation depends on the wage gap 
$\zeta_{t}-\zeta_{t}^{p o t}$ in addition to the employment gap $x_{L t}$. Even a policy that closed the employment (or output) gap would imply pressure on inflation if real wages did not immediately adjust to their potential level, implying a policymaker tradeoff between stabilizing inflation and the employment gap. As might be expected, the size of the real wage gap matters for this tradeoff, and for the transmission of shocks to inflation. Because the actual real wage adjusts sluggishly, the behavior of the wage gap depends critically on the potential real wage, which varies with openness. Accordingly, to the extent that openness reduces variation in the potential real wage - as under our benchmark calibration - greater openness can be expected to reduce the real wage gap associated with a zero employment gap, allowing policymakers to come closer to stabilizing both employment and inflation. But recalling Tables 1 and 2, openness does not exert large quantitative effects on $\zeta_{t}^{\text {pot }}$ under reasonable calibrations: even with the high Frisch elasticity of unity, increased openness only has a modest effect in dampening the response of $\zeta_{t}^{\text {pot }}$ to real shocks.

Notwithstanding that it is helpful for economic interpretation to think of openness as operating through several channels that affect aggregate supply and demand, it is bears emphasizing that the composite parameter $\sigma^{\text {open }}$ provides a summary statistic for how the model economy is affected by openness. As an implication, differences between closed and open economy responses - including of nominal variables such as inflation - can only be substantial under conditions that induce a significant disparity between $\sigma^{\text {open }}$ and the intertemporal substitution elasticity $\sigma$. Moreover, while such a wedge is clearly a sufficient condition for the IS curve (31) to be affected by openness, the effects of openness on the AS block still tend to be quite small under plausible calibrations of the Frisch elasticity of labor supply.

These considerations are useful in interpreting how impulse responses to the same three shocks considered above in our SIGMA simulations depend on the openness of the economy. Figure 6 compares responses to a 1 percentage point decline in the inflation target under three calibrations of openness, ranging from a trade share of 1 percent of GDP under the "nearly closed" calibration, to 12 percent under our benchmark, to 35 percent under 'high 
openness." ${ }^{19}$ It is evident that output contracts by a somewhat larger amount in the highly open economy. The larger output contraction occurs because the target reduction causes a rise in real interest rates, and the interest-sensitivity of output rises with greater openness in our benchmark calibration (quantitatively, the interest-sensitivity $\sigma^{\text {open }}\left(1-g_{y}\right)$ rises from $0.5^{*}(1-.18)=0.41$ under the "nearly closed" calibration to 0.90 in the high openness case). Price inflation also falls a bit more as openness increases, reflecting the larger output contraction; however, the low sensitivity of marginal cost to the employment gap (i.e., $\lambda_{m p l}$ in equation (34) is only 0.35 ) accounts for the small quantitative differences in the responses. ${ }^{20}$ Overall, given the wide differences in the trade shares, the responses of aggregate output, inflation, and the real interest rate seem quite unresponsive to openness. The main differences are that exports account for a larger share of the output contraction as openness increases (i.e., exports/GDP fall by more), and that consumer price inflation falls more abruptly in the highly open economy (as the real exchange rate appreciation exerts a larger effect given the greater share of imported goods in the household consumption bundle).

Figure 7 compares the effects of a rise in government spending across the three calibrations. The responses of output and inflation diverge noticeably with openness, with output and inflation rising much less under the high openness calibration. Because the Taylor rule keeps output close to potential $\left(y^{p o t}\right)$, the differences in the output responses mainly reflect that the wealth effect on labor supply is smaller in a relatively open economy (as noted in our discussion of the flexible price equilibrium). Given sluggish wage adjustment, the smaller output expansion in turn reduces pressure on marginal cost in the more open economy. In terms of our discussion of (38), the real wage gap $\zeta_{t}-\zeta_{t}^{\text {pot }}$ is smaller and less persistent in a relatively open economy (as $\zeta^{\text {pot }}$ falls by less), and hence generates weaker pressure on

\footnotetext{
${ }^{19}$ The simulations are derived in the two country version of the model in which the home country constitutes 25 percent of world output. However, it makes little difference to our results if the relative size of the home country were set close to zero (even in the high openness case, we found that the sensitivity of the simulation results to the relative size of the home economy is quite small.)

${ }^{20}$ Moreover, as suggested by our discussion above, differences in the MRS slope due to openness have little influence on the real wage response. Thus, with the potential real wage unaffected by the shock, the real wage gap in equation (38) behaves similarly irrespective of openness, so that marginal cost depends mainly on the response of the employment (or output) gap.
} 
inflation. Finally, the higher interest-elasticity of aggregate demand translates into less real interest rate adjustment in the highly open economy.

Figure 8 compares the effects of a highly persistent rise in technology. The response of output is somewhat larger in the highly open calibration, while the response of the real wage is smaller. To understand this, recall from our discussion of the flexible price equilibrium that greater openness (assuming $\eta_{c}>\sigma$ as under our benchmark calibration) tends to damp the wealth effect of the shock on labor supply. This boosts potential output - and thus accounts for some of the larger output increase in the figure in the high openness case while reducing the rise in the flexible price real wage. The smaller real wage gap (in absolute value) helps account for some of the less pronounced decline in inflation. In addition, as we discuss in Section 3.8, some of the disparity in the output and inflation responses reflects that the Taylor rule in effect fails to account for the higher interest-sensitivity of the economy as openness increases; thus, an alternative policy that kept output at potential would imply a smaller disparity in the output and inflation responses than depicted in the figure.

But notwithstanding some differences, the salient feature of the foregoing results is that even substantial variation in openness seems to have fairly small effects on the responses, except in the case of the government spending shock. Moreover, the SIGMA simulations discussed in Section 2 indicate that some of the disparities in the responses to the fiscal shock would narrow with the inclusion of endogenous capital, and adjustment costs on the expenditure components; notably, endogenous capital would reduce the pronounced disparity between the interest elasticity of private absorption and of trade flows under our benchmark calibration, so that the interest elasticity of demand would rise by less as openness increased.

We conclude this section by illustrating a case in which openness exerts fairly dramatic effects on the impulse responses of the model. In particular, Figure 9 shows responses to the technology shock under an alternative calibration that imposes a very high trade price elasticity of 6 , and a Frisch elasticity of labor supply of unity. As seen in Table 2, the parameter $\sigma^{\text {open }}$ rises from 0.5 under the "nearly closed" calibration to 3.6 in the high openness case, consistent with roughly a halving of the slope of the MRS schedule (from 
3.5 to 1.8 ). Given that the wealth effect on labor supply diminishes rapidly with greater openness under this calibration, output exhibits a much more pronounced rise in the highly open economy. The smaller rise in the real wage in the highly open economy implies a much smaller real wage gap (in absolute value), and accounts for why inflation falls only about half as much on impact as in the closed economy. Accordingly, as suggested by the figure, a policymaker concerned about the variability of domestic price inflation and the output gap would face a markedly improved tradeoff locus in the open economy. However, we emphasize that this large divergence hinges on a high Frisch elasticity of labor supply, and a fairly extreme assumption about the trade price elasticity.

\subsection{Variance Tradeoff Frontiers}

A limitation of our preceding analysis that characterized policy as following a simple (Taylorstyle) interest rate reaction function is that it is difficult to disentangle what components of the transmission channel change with trade openness. In particular, it is hard to ascertain whether differences are attributable to disparities in the "IS" block of the model, i.e., in the interest-sensitivity of the economy, or in the equations governing aggregate supply.

Toward this end, it is useful to follow Taylor (1979) in characterizing the variance tradeoff frontier of the home economy. Accordingly, we assume that the monetary policy of the home country is determined by an optimal targeting rule that minimizes the following quadratic discounted loss function:

$$
\mathbb{E}_{t} \sum_{j=0}^{\infty} \beta^{j}\left(\pi_{t+j}^{2}+\lambda_{x} x_{t+j}^{2}\right),
$$

where $\lambda_{x}$ is the relative weight on the output gap. The policymaker is assumed to minimize the loss function subject to the log-linearized behavioral equations of the model, while taking as given that monetary policy in the foreign economy continues to follow a Taylor rule. ${ }^{21}$

\footnotetext{
${ }^{21}$ The variance tradeoff frontier is not very sensitive to the relative size of the home country. Hence, although we derive our results assuming that the home country constitutes 25 percent of world output, the tradeoff frontiers are not markedly different in the case in which the home country share of world output is close to zero. In the latter case, the policymaker tradeoff frontier can be derived by minimizing the loss
} 
This case parallels related analysis in a closed economy setting (as in Clarida, Galí, and Gertler (1999) and Woodford (2003)) insofar as the optimal policy does not depend on the model's IS curve (at least given our assumption that the policymaker's loss function does not penalize interest rate variability).

The left panel of Figure 10 shows a policy tradeoff frontier between inflation and output gap variability for the case of a technology shock. The tradeoff frontier is obtained by minimizing the policymaker's loss function (39) over all possible values of $\lambda_{x}$ subject to the log-linearized behavioral equations. ${ }^{22}$ For visual clarity, the tradeoff frontiers are shown only for the alternative calibrations of a highly open economy (in which the trade share is 35 percent), and the nearly closed case (with a trade share of 1 percent). Under either calibration, the standard deviation of inflation declines to zero as the policymaker's weight on the output gap $\lambda_{x}$ declines to zero, while the standard deviation of the output gap declines to zero as $\lambda_{x}$ approaches infinity.

As is familiar from closed-economy analysis, the presence of wage rigidities gives rise to a tradeoff between stabilizing the output gap and inflation. However, the striking feature of the figure is that the tradeoff frontiers are virtually identical, notwithstanding very pronounced differences in trade openness. This similarity reflects that the only channels through which trade openness can influence the tradeoff frontier is by affecting the slope of the MRS schedule (recalling the MPL is invariant), or by affecting the potential real wage $\zeta_{t}^{p o t}$; as noted above, while openness affects the slope of the IS curve and potential real interest rate $r_{t}^{\text {pot }}$, this is inconsequential for a policymaker loss function such as (39) that does not explicitly depend on the interest rate. Thus, insofar as it is clear from Table 1 that the potential real wage and slope of the MRS show little variation with openness under our benchmark calibration, it is unsurprising that the policy frontiers are nearly identical.

Although the policy tradeoff frontiers are nearly identical, the right panel - which plots function subject to the behavioral equations (31)- (36) that apply in the small open economy variant of our model.

${ }^{22}$ Note that the vertical axis shows the standard deviation of inflation, and the horizontal axis the standard deviation of the output gap. 
how interest rate volatility varies with $\lambda_{x}$ - shows that implementation of the policy implies considerably less real interest variation in the more open economy. ${ }^{23}$ This simply reflects that openness markedly raises the interest sensitivity of the economy, even if not the slope of the MRS schedule and $\zeta_{t}^{\text {pot }}$ (as seen from Table 1, $\sigma^{\text {open }}$ rises from 0.5 in the closed economy case to 1.1 when the trade share is 35 percent). Thus, some of the relatively small differences in the transmission of the technology shock shown in Figure 8 are in fact attributable to the aggregate demand block of the model. For example, the optimal rule that puts a high enough weight on output gap stabilization to keep output at potential (i.e., a very large $\lambda_{x}$ ) implies output and inflation responses that are even closer than those depicted in Figure 8 (as easily verified by plotting impulse responses for this calibration of the optimal rule).

Figure 11 considers how the highly open and closed economy policy frontiers shift given changes in key structural parameters that affect the slope of the MRS schedule. The upper panel shows that even adopting an extremely high value of the trade price elasticity $\eta_{c}$ of 3, and a fairly high Frisch elasticity of labor supply of 0.5 (i.e., $\chi=2$ ), is not sufficient to induce much of a disparity between the tradeoff frontiers. Not surprisingly, the high trade price elasticity does drive a large wedge in the variability of the interest rate response associated with any given policy rule, i.e., value of $\lambda_{x}$.

The policy frontiers may show considerable more variation with openness, but only under rather extreme calibrations. Thus, the middle panel shows that the open economy tradeoff frontier would move further inside the (nearly) closed economy frontier in the case in which both the trade price elasticity and Frisch elasticity of labor supply are extremely high $\left(\eta_{c}=6\right.$, and the value of $\chi$ of .05 implies a Frisch elasticity of 20). In this case, the wealth effect dominates the behavior of the MRS slope, so that the latter flattens considerably with openness. Provided that the MPL slopes downward enough, the response of the potential real wage is damped considerably as openness increases; and because real wages are sticky, this improves the tradeoff locus open to policymakers in the highly open economy. However,

\footnotetext{
${ }^{23}$ Note that Figures 10 and 11 depict the relative weight on the output gap using an exponential scale, so that e.g., the tick label -5 corresponds to a weight of unity on inflation, and $\exp (-5)$ on the output gap.
} 
the manner in which the tradeoff frontier varies with openness in an environment with an extremely flat MRS tends to be quite sensitive to the slope of the MPL schedule (unlike under our benchmark, in which the frontier is much less sensitive to the slope of the MPL). As illustrated by the last panel, the open economy tradeoff frontier actually lies well outside the closed economy frontier if the MPL slope is reduced to 0.05 in absolute value.

\section{Alternative Model Specifications}

Our workhorse model made a number of simplifying assumptions to keep the analysis tractable. We now investigate the robustness of these conclusions to several extensions of the model, including incomplete asset markets, endogenous capital accumulation, imported intermediate goods, and local currency pricing.

\subsection{Incomplete International Financial Markets}

Our baseline model assumes that asset markets are complete both domestically and internationally. However, as this is an extreme assumption, we now consider an alternative in which households only have access to a non-state contingent international bond.

Under this alternative, the household's budget constraint can be expressed as:

$$
\begin{gathered}
P_{C t} C_{t}(h)+\int_{s} \xi_{D t, t+1} B_{D t+1}(h)+\frac{e_{t} P_{F t}^{*} B_{F t+1}(h)}{\phi_{F t}\left(b_{F t+1}\right)}=W_{t}(h) N_{t}(h)+R_{K t} K+ \\
\Gamma_{t}(h)-T_{t}(h)+B_{D t}(h)+e_{t} B_{F t}(h) .
\end{gathered}
$$

where $B_{F t+1}(h)$ denotes the household's purchases of the foreign bond, $P_{F t}^{*}$ is the price of the foreign bond (in foreign currency), and $B_{D t+1}(h)$ denotes state-contingent bonds traded amongst domestic households. We follow Turnovsky (1985) and assume there is an intermediation cost, $\phi_{F}\left(b_{F t+1}\right)$, paid by domestic households for purchases of the international bond to ensure that net foreign assets are stationary. ${ }^{24}$ This intermediation cost depends on the ratio of economy wide holdings of net foreign assets to nominal output $\left(b_{F t+1}\right)$ :

$$
\phi_{F}\left(b_{F t+1}\right)=\exp \left(-v_{F} \frac{e_{t} P_{F t}^{*} B_{F t+1}(h)}{P_{D t} Y_{t}}\right)
$$

\footnotetext{
24 This intermediation cost is asymmetric, as foreign households do not face this cost; rather, they collect profits on the monopoly rents associated with the intermediation costs.
} 
and rises when the home country is a net debtor. We set $v_{F}$ to be very small $\left(v_{F}=0.001\right)$, which effectively implies that uncovered interest rate parity holds in our model.

Given this alternative financial structure, the risk sharing condition (i.e., equation (20)) no longer holds and the domestic economy's level of net foreign assets influences model dynamics. To understand how, we begin by considering the demand side of the model. As in Section 3, it remains possible to derive a (log-linearized) open-economy IS curve of the form:

$$
y_{t}=\mathbb{E}_{t} y_{t+1}-\left(1-g_{y}\right) \sigma^{o p e n}\left\{r_{t}-r_{t}^{*}\right\}+\epsilon_{b_{F}} b_{F t+1}+u_{I S t}
$$

where $\epsilon_{b_{F}}=\left(1-g_{y}\right)\left(\sigma\left(1-\omega_{c}\right)-\sigma^{o p e n}\right) v_{F}$, and $u_{I S t}=g_{y}\left(g_{t}-\mathbb{E}_{t} g_{t+1}\right)+\left(1-g_{y}\right)\left(c_{t}^{*}-\mathbb{E}_{t} c_{t+1}^{*}\right)$. This expression for the IS curve is the same as in the workhorse model (expression (25)) except that it involves the home country's net foreign asset position due to the presence of the intermediation cost. Since we set $v_{F}$ to be very small, $\epsilon_{b_{F}}$ is very small, and the IS curve is virtually unchanged vis-á-vis the workhorse model.

Under incomplete markets, however, the IS curve does not provide a complete description of aggregate demand. Intuitively, the IS curve determines how aggregate demand grows through time, but the current level is only pinned down by the intertemporal budget constraints of households, which at a national level constrains the evolution of net foreign assets. Accordingly, the aggregate demand block also includes a (log-linearized) law of motion specifying how net foreign assets $b_{F t+1}$ evolve given the home country's net savings $n s_{t}$ :

$$
b_{F t+1}=\frac{1}{\beta} b_{F t}+\frac{1}{1-g_{y}} n s_{t},
$$

where $n s_{t}$ is the country's total income less household and government expenditures (i.e., $\left.n s_{t}=\left[y_{t}-\left(1-g_{y}\right) c_{t}-g_{y} g_{c t}-\left(1-g_{y}\right) \omega_{c} \tau_{t}\right]\right)$. Because consumption depends only on output and the terms of trade (given the resource constraint and equation for real net exports), net savings can also be expressed simply in terms of output and the terms of trade. Finally, the terms of trade are determined by a modified uncovered interest parity (UIP) condition, which is the same as in the workhorse model except that it reflects the presence of the 
intermediation cost:

$$
\tau_{t}=\mathbb{E}_{t} \tau_{t+1}+r_{t}^{*}-r_{t}-v_{F} b_{F t+1}=\left(r_{L t}^{*}-r_{L t}\right)-v_{F} \mathbb{E}_{t} \sum_{j=0}^{\infty} b_{F t+j+1},
$$

where $r_{L t}$ corresponds to the domestic long-term real interest rate (see equation (24)).

Turning to aggregate supply, the MPL schedule remains unchanged under incomplete markets, as discussed in Section 3. However, the MRS schedule is influenced by the country's ability to borrow and lend, so that changes in the home country's net foreign asset position influence aggregate supply. In particular, the marginal rate of substitution (in product terms) can be written as:

$$
m r s_{t}=\chi L_{t}+\frac{1}{\sigma} \frac{1}{1-g_{y}}\left((1-\alpha)\left(L_{t}+z_{t}\right)-g_{y} g_{c t}\right)-\frac{1}{\sigma} \frac{1}{1-g_{y}} n s_{t}-\left(\frac{1}{\sigma}-1\right) \tau_{t} .
$$

This expression for the marginal rate of substitution is similar to the one for the closed economy (i.e., equation (29)), except for the inclusion of the last two terms involving net savings and the terms of trade. Clearly, for the special case of $\sigma=1$, the terms of trade drops from the above equation, so that the only difference between the closed and open economy expression for the marginal rate of substitution involves the term in net savings. An increase in net savings, all else equal, lowers the marginal rate of substitution, which under flexible prices and wages, lowers the product real wage. By contrast, this effect is absent in a closed economy, since $n s_{t}=0$.

The above discussion suggests that the effects of domestic shocks may diverge considerably between a closed and open economy if the IS curve slope is sensitive to the degree of trade openness (for the same reasons discussed in Section 3), or if the shocks exert large effects on net savings. To investigate the quantitative effects of openness under our benchmark calibration, the right column of Figure 12 shows the responses of output, domestic inflation, and consumption to a persistent rise in technology (the $\mathrm{AR}(1)$ coefficient equals 0.97) for different degrees of trade openness under incomplete markets; for point of reference, corresponding results under complete markets are shown in the left column. Clearly, under either financial structure, technology shocks have somewhat larger effects on output, and 
smaller effects on inflation, as the openness of the economy increases. This reflects that openness damps the expansion in consumption under either financial market structure: under complete markets, because of insurance arrangements, while under incomplete markets it reflects an increase in desired saving because current income exceeds permanent income. As observed in Section 3, the smaller implied wealth effect on labor supply translates into a larger output response, and mitigates the decline in inflation. Nevertheless, the differences in the responses of output and inflation appear fairly small given the large changes in openness examined. The modest size of the disparities reflects that home and foreign goods are not substitutable enough in our benchmark calibration to have large effects on the MRS schedule (i.e., net savings does not change enough to exert much of an effect on the MRS schedule given by equation (45)).

To demonstrate that there can potentially be large differences between an open and closed economy under incomplete markets, Figure 13 shows the effects of a more transitory technology shock (the $\mathrm{AR}(1)$ coefficient equals 0.8 ) on output under three alternative calibrations of the trade price elasticity and the Frisch labor supply elasticity. We consider a transitory shock rather than a permanent shock, because, regardless of the degree of openness, consumption will rise immediately to its new higher level in response to a permanent shock without any change in aggregate savings.

The top panel shows the effect on output under a trade price elasticity of 6 (keeping the Frisch elasticity at its benchmark value of 0.2 , so $\chi=5$ ). The combination of the more transient shock and greater substitutability between home and foreign goods generates a larger increase in net savings in the domestic economy, and hence larger output differences than under the benchmark calibration. As shown in the middle and lower panels, these differences in the output responses become even larger as the labor supply curve becomes more elastic (i.e., a lower value of $\chi$ ) and as the trade price elasticity increases. However, it bears reiterating that rather extreme calibrations of the trade price elasticity (and a high Frisch elasticity) seem required for the responses to show large divergence based on openness. 


\subsection{Endogenous Investment}

We next investigate the robustness of our results to including endogenous investment into the workhorse model of Section 3. In the modified framework, households augment their stock of capital according to:

$$
K_{t+1}(h)=(1-\delta) K_{t}(h)+I_{t}(h),
$$

where $I_{t}(h)$ and $K_{t}(h)$ denote household investment and the beginning of period $t$ stock of capital, respectively. The household budget constraint is also modified to reflect investment purchases:

$$
\begin{gathered}
P_{C t} C_{t}(h)+P_{C t} I_{t}(h)+\int_{s} \xi_{t, t+1} B_{t+1}(h)=W_{t}(h) N_{t}(h)+R_{K t} K_{t}(h)+ \\
\Gamma_{t}(h)-T_{t}(h)+B_{t}(h)-P_{D t} \phi_{I t}(h) .
\end{gathered}
$$

In equation (47), $\phi_{I t}$ denotes an adjustment cost given by:

$$
\phi_{I t}(h)=\frac{\phi_{I}}{2} \frac{\left(I_{t}(h)-I_{t-1}(h)\right)^{2}}{I_{t-1}(h)} .
$$

Following Christiano, Eichenbaum, and Evans (2005), it is costly to change the level of investment from the previous period. Investment goods are produced using the same technology as final consumption goods (see equation (13)), and hence require both the domesticallyproduced composite good as well as imports. The import share of investment goods and elasticity of substitution between domestic goods and imports in the production function for investment is assumed to be the same as for consumption.

The inclusion of endogenous investment tends to markedly boost the interest-sensitivity of domestic demand under plausible calibrations. Accordingly, as suggested by the SIGMA simulations in Section 2, the interest-sensitivity should be expected to rise less steeply with openness compared with the workhorse model; in fact, the aggregate interest-sensitivity of the economy can even decline with greater openness if investment is sufficiently interestsensitive.

To illustrate these points, the upper panel of Figure 14 reexamines the reduction in the inflation target shock in the augmented model with investment. The calibration in the top 
panel sets the adjustment cost on investment parameter $\phi_{I}=0.2$, which effectively serves to equalize the interest elasticity of domestic demand and of real net exports (notwithstanding that the interest elasticity of consumption is unchanged from our benchmark calibration). In contrast to the model with fixed capital (see Figure 6), which implied a modestly larger output contraction in the highly open economy relative to the closed economy, the response of both output and inflation is nearly invariant to trade openness . The virtually identical output responses reflect that the effective interest sensitivity of domestic demand is very close to that of real net exports, so that putting a higher weight on the latter as trade openness rises has little effect on the overall interest sensitivity of the economy. The similar output responses across the calibrations translate into commensurate effects on marginal cost and inflation.

The two lower panels consider alternative calibrations which show that the general conditions highlighted in Section 3 as potentially giving rise to large differences between closed and open economies continue to remain operative under endogenous capital accumulation. Thus, the middle panel considers the case in which the trade price elasticity is set to 6 , rather than 1.5 as in our benchmark. In this case, the interest-sensitivity of real net exports is much higher than that of domestic demand, so that the aggregate interest-sensitivity of the economy rises with openness, and output shows a larger contraction as openness increases. The final panel keeps the trade price elasticity at its benchmark value of 1.5 , but increases the effective interest-sensitivity of domestic demand relative to the first panel by reducing the adjustment cost parameter $\phi_{I}$ to 0.01 . In this case, output contracts by somewhat more in the closed than in the open economy.

\subsection{Imported Materials}

Our workhorse model treats imports as finished goods. However, many imported goods are used as intermediate inputs in production, and their use in production may alter the transmission of domestic shocks.

To investigate this possibility, we follow McCallum and Nelson (1999) and modify the 
production process of intermediate goods producers discussed in Section 3 so that gross output of intermediate good $i, Y_{t}(i)$, is produced according to the CES gross production function:

$$
Y_{t}(i)=\left(\left(1-\omega_{L}\right)^{\frac{\rho_{L}}{1+\rho_{L}}}\left(K_{t}(i)^{\alpha}\left(Z_{t} L_{t}(i)\right)^{1-\alpha}\right)^{\frac{1}{1+\rho_{L}}}+\omega_{L}^{\frac{\rho_{L}}{1+\rho_{L}}} M_{Y t}(i)^{\frac{1}{1+\rho_{L}}}\right)^{1+\rho_{L}} .
$$

In the above, value-added for good $i$ is produced via a Cobb-Douglas production function and combined with firm i's purchases of the foreign aggregate good used as intermediate inputs, $M_{Y t}(i)$ to produce the gross output of good $i$. Also, the parameter $\omega_{L}$ determines the share of imported materials in gross production, and $\eta_{L}=\frac{1+\rho_{L}}{\rho_{L}}$ is the elasticity of substitution between value-added and imported materials. We assume that capital, labor, and imported materials are perfectly mobile across firms within a country so that all firms have identical marginal costs per unit of gross output $\left(M C_{t}\right)$ :

$$
M C_{t}=\left(\left(1-\omega_{L}\right) M C_{V t}^{-\frac{1}{\rho_{L}}}+\omega_{L} P_{M t}^{-\frac{1}{\rho_{L}}}\right)^{-\rho_{L}}
$$

where $M C_{V t}$ is marginal cost per unit of value-added defined earlier as equation (10).

The inclusion of intermediate inputs in the model changes the home economy's resource constraint so that:

$$
Y_{t}=C_{D t}+G_{t}+\frac{\zeta^{*}}{\zeta}\left(M_{C t}^{*}+M_{Y t}^{*}\right)
$$

where $M_{Y t}^{*}$ denote exports of the domestic good used as an intermediate inputs. Market clearing in the factor market for intermediate inputs is given by:

$$
M_{Y t}=\int_{0}^{1} M_{Y t}(i) d i
$$

Relative to the workhorse model, allowing for fluctuations in imported materials provides another channel through which openness affects the MPL schedule. In particular, a terms of trade appreciation increases labor demand by an amount that depends crucially on the value of $\omega_{L}$.

An additional channel through which imported materials affects the domestic economy is by altering the sensitivity of demand to interest rates. As discussed in the Appendix, under 
the assumption of flexible wages and $\alpha=0$ so that value added is linear in labor, the IS curve is given by:

$$
y_{t}=\mathbb{E}_{t} y_{t+1}-\left(1-g_{y}\right) \sigma_{M}^{\text {open }}\left\{r_{t}-r_{t}^{*}\right\}+u_{I S t},
$$

where $u_{I S t}$ is a term reflecting the government spending shock and foreign shocks. This expression confirms that it remains possible to follow the basic logic of Section 3 to derive a new composite parameter, $\sigma_{M}^{\text {open }}$, which has the interpretation of the elasticity of aggregate demand to real interest rates. This elasticity $\sigma_{M}^{\text {open }}$ can be related to the one obtained in the workhorse model, $\sigma^{\text {open }}$, as follows: $\sigma_{M}^{\text {open }}=\sigma^{\text {open }}\left(1-\omega_{L}\right)+\omega_{L} \frac{\eta_{L}}{\left(1-g_{y}\right)}$. Accordingly, the interest rate sensitivity of demand can be regarded as a weighted average of the interest-sensitivity of consumption, real net exports of final goods, and real net exports of intermediate inputs.

Because the elasticity of substitution between value added and materials is fairly low, the inclusion of imported materials can reduce the difference in interest-rate elasticities of demand between an open and closed economy. For example, consider a share of imported materials in gross production of 5 percent $\left(\omega_{L}=0.05\right)$, and elasticity of substitution between value added and materials of $1 / 3$, as in McCallum and Nelson (1999). With these values along with our benchmark values for $\sigma=0.5, \omega_{c}=0.12, \eta_{c}=1.5$, and $g_{y}=0.18$, then $\sigma_{M}^{\text {open }}=0.70$ instead of $\sigma^{\text {open }}=0.72$.

The presence of imported materials also affects the pricing decisions of intermediate producers by altering their marginal costs. In particular, producers set gross output prices in a staggered fashion rather than value-added prices, and the first order condition for the price of good $i$ is:

$$
\mathbb{E}_{t} \sum_{j=0}^{\infty} \psi_{t, t+j} \xi_{p}^{j}\left(\frac{\left(1+\tau_{p}\right) V_{D t+j} P_{D t}(i)}{\left(1+\theta_{p}\right)}-M C_{G t+j}\right) Y_{t+j}(i)=0,
$$

where $P_{D t}(i)$ now has an interpretation as a gross output price and $V_{D t+j}=\prod_{h=1}^{j} \pi_{t+h-1}$. Equation (54) can be log-linearized and rewritten as:

$$
\pi_{t}-\pi_{t-1}=\beta\left(\pi_{t+1 \mid t}-\pi_{t}\right)+\kappa_{p}\left[\left(1-\omega_{L}\right)\left(\zeta_{t}-m p l_{t}\right)+\omega_{L} \tau_{t}\right]
$$


where $m p l_{t}=(1-\alpha) z_{t}-\alpha L_{t}$, corresponds to the marginal product of labor - in terms of value added - described in Section 3. In the previous expression we have written the marginal cost in terms of the value-added output to make clear that with imported materials, gross output price inflation depends on fluctuations in the terms of trade.

Relative to the workhorse model, allowing for fluctuations in imported materials has two effects on the price equation. First, the presence of materials inputs contribute to reducing the pass-through from marginal cost to prices, thus resulting in smaller price adjustments in response to higher nominal aggregate demand. Second, since a more open economy may be associated with a high fraction of imported materials in gross output production (i.e, a larger $\omega_{L}$ ), fluctuations in the terms of trade may have a greater influence on gross output price inflation than in a closed economy.

To investigate the quantitative importance of imported materials, Figure 15 shows the effects of a technology shock for different degrees of openness. In each case, we set $\eta_{L}=\frac{1}{3}$ and calibrated $\omega_{c}$ and $\omega_{L}$ so that material imports account for roughly 25 percent of total imports in each economy. ${ }^{25}$ As in the workhorse model, the highly open economy experiences a larger increase in output and smaller decline in inflation. The inclusion of intermediate inputs tends to dampen the fall in inflation in response to the technology shock, reflecting that the fall in unit labor costs is offset to a greater degree by higher import prices. However, the differences between the highly open economy and the closed economy do not appear large, so that the inclusion of intermediate goods only modestly amplifies the differences evident in the workhorse model.

\subsection{Pricing To Market}

Our workhorse model assumed that the law of one price holds for each intermediate good. However, there is considerable empirical evidence suggesting that the law of one price does

\footnotetext{
${ }^{25}$ In the model with material imports, we vary both $\omega_{c}$ and $\omega_{L}$ to alter the ratio of imports to GDP in each scenario. As a result, the more open economy is characterized by larger values of both $\omega_{c}$ and $\omega_{L}$; however, the fraction of material imports to overall imports is held fixed at 25 percent in all cases. Finally, the simulations shown in Figure 15 restrict $\alpha=0$, but otherwise adopt the values used in our benchmark calibration.
} 
not hold. A related literature emphasizes that U.S. import prices at the point of entry respond less than one for one with a change in the exchange rate (i.e., exchange rate passthrough to U.S. import prices is incomplete). ${ }^{26}$ We now consider an alternative version of our model which can account for these findings.

In this alternative version, intermediate goods firms set different prices at home and abroad or 'price to market'. This pricing to market behavior arises for two reasons. First, we assume, as in Betts and Devereux (1996), intermediate goods' prices are sticky in local currency terms. We also work with aggregators for intermediate goods that have non-constant elasticities of demand as in Kimball (1995), implying that a firm may face different demand elasticities at home and abroad. ${ }^{27}$

To incorporate these features, we modify the problem of the consumption goods distributor who purchases all of the intermediate goods both at home and abroad to produce a final good that can be used either for private consumption, $C_{t}$, or government consumption, $G_{t}$. Using the demand aggregator discussed in Gust, Leduc, and Vigfusson (2006), the final consumption good distributor's demand for imported and domestic good $i$ is given by:

$$
\begin{gathered}
M_{C t}(i)=\omega_{c}\left[\frac{1}{1-\nu}\left(\frac{P_{M t}(i)}{P_{M t}}\right)^{\frac{1}{1-\gamma}}\left(\frac{P_{M t}}{P_{F t}}\right)^{\frac{\rho}{\gamma-\rho}}-\frac{\nu}{1-\nu}\right]\left(C_{t}+G_{t}\right), \\
C_{D t}(i)=\left(1-\omega_{c}\right)\left[\frac{1}{1-\nu}\left(\frac{P_{D t}(i)}{P_{D t}}\right)^{\frac{1}{1-\gamma}}\left(\frac{P_{D t}}{P_{F t}}\right)^{\frac{\rho}{\gamma-\rho}}-\frac{\nu}{1-\nu}\right]\left(C_{t}+G_{t}\right) .
\end{gathered}
$$

As in Dotsey and King (2005), when $\nu \neq 0$, these demand curves have a linear term which implies that the elasticity of demand of producer $i$ depends on its price $P_{D t}(i)$ relative to an index of the prices of its competitors (see below). When $\nu=0$, the demand elasticity is constant and $\frac{1}{1-\gamma}$ has the interpretation as the elasticity of substitution between home brands (i.e., $\frac{1-\gamma}{\gamma}$ is equivalent to $\theta_{P}$ in the workhorse model). $P_{M t}$ and $P_{D t}$ are price indices

\footnotetext{
${ }^{26}$ For a survey of this literature, see Goldberg and Knetter (1997), and for more recent empirical evidence for the United States, see Marazzi, Sheets, and Vigfusson (2005).

27 See Bergin and Feenstra (2001) for a discussion of how the interaction of demand curves with nonconstant elasticities with sticky prices can be helpful in accounting for exchange rate dynamics.
} 
of domestic and imported goods given by:

$$
P_{D t}=\left(\int_{0}^{1} P_{D t}(i)^{\frac{\gamma}{\gamma-1}} d i\right)^{\frac{\gamma-1}{\gamma}} \quad \text { and } \quad P_{M t}=\left(\int_{0}^{1} P_{M t}(i)^{\frac{\gamma}{\gamma-1}} d i\right)^{\frac{\gamma-1}{\gamma}}
$$

while $P_{F t}$ is a price index consisting of all the prices of a firm's competitors:

$$
P_{F t}=\left[\left(1-\omega_{c}\right) P_{D t}^{\frac{\gamma}{\gamma-\rho}}+\omega_{c} P_{M t}^{\frac{\gamma}{\gamma-\rho}}\right]^{\frac{\gamma-\rho}{\gamma}}
$$

Intermediate goods producers sell their products to the consumption goods distributors and can charge different prices at home and abroad. These prices are determined according to Calvo-style contracts subject to indexation. The first order condition associated with the optimal setting of the domestic price of intermediate good $i$ (i.e., $P_{D t}(i)$ ) is given by:

$$
\mathbb{E}_{t} \sum_{j=0}^{\infty} \psi_{t, t+j} \xi_{p}^{j}\left[1-\left(1-\frac{M C_{t+j}}{\left(1+\tau_{P}\right) V_{D t+j} P_{D t}(i)}\right) \epsilon_{D t+j}(i)\right] V_{D t+j} C_{D t+j}=0,
$$

where the elasticity of demand for good $i$ in the domestic market is:

$$
\epsilon_{D t}(i)=\frac{1}{1-\gamma}\left[1-\nu\left(\frac{P_{D t}(i)}{P_{D t}}\right)^{\frac{1}{1-\gamma}}\left(\frac{P_{D t}}{P_{F t}}\right)^{\frac{\rho}{\rho-\gamma}}\right]^{-1}
$$

With $\nu>0$, as in Kimball (1995), $\epsilon_{D t}(i)$ may be an increasing function of a firm's price relative to its competitors, and a firm will not want its desired price (i.e., its optimal price in the absence of price rigidities) to deviate too far from its competitors.

Equation (60) can be log-linearized and expressed as:

$$
\pi_{t}-\pi_{t-1}=\beta\left(\pi_{t+1 \mid t}-\pi_{t}\right)+\kappa_{p} \Theta\left[\zeta_{t}-m p l_{t}+\nu \mu \omega_{C} \eta_{c}\left(p_{M t}-p_{D t}\right)\right]
$$

where $\mu=\frac{1}{\epsilon_{D}-1}$ denotes the steady state (net) markup over marginal cost, $\epsilon_{D}=\frac{1}{(1-\gamma)(1-\nu)}$ is the steady state value of $\epsilon_{D t}(i)$, and $\eta_{c}=\frac{\rho}{(\rho-\gamma)(1-\nu)}$ denotes the aggregate elasticity between home and foreign goods in steady state. The parameter $\Theta=\frac{1}{1+\nu(1+\mu)}<1$ reflects the degree of 'strategic' complementarity in price-setting (e.g., Woodford (2003)). That is, with $\nu=0$, a firm's demand elasticity is constant, and this expression is the same as in the workhorse model. With $\nu>0$, there are variations in desired markups associated with changes in a 
firm's price relative to its competitors. In this case, inflation is less sensitive to marginal cost, and in the open economy more sensitive to foreign prices. Furthermore, the importance of foreign prices in affecting domestic inflation depends directly on the degree of openness, $\omega_{C} \cdot$

According to equation (62), foreign competition can influence domestic inflation through changes in desired markups. This expression is reminiscent of Dornbusch and Fischer (1984), who described how foreign competition could influence the desired markups of domestic firms and effectively change the slope of the Phillips curve. In particular, they argued that monetary shocks were likely to cause domestic prices in an open economy to respond more quickly, which they interpreted as a steepening of the slope of the Phillips Curve. From a qualitative perspective, monetary policy shocks can also steepen the Phillips curve in our model with variable markups. In particular, a monetary contraction occurring in response to a decrease in the central bank's inflation target lowers marginal cost and generates a real appreciation of the domestic currency. This appreciation lowers import prices relative to domestic prices, and domestic producers respond by reducing their desired markups. As a result, domestic price inflation can appear more sensitive to the fall in demand associated with the monetary contraction.

However, we emphasize that the source of the shock in our framework has crucial bearing for the question of whether inflation becomes more or less sensitive to aggregate demand. For example, in response to a government spending shock, inflation can appear less sensitive to demand. Higher government spending puts upward pressure on marginal cost but the real exchange rate appreciates. This appreciation reduces relative import prices, forcing domestic producers to lower their desired markups. This reduction in desired markups has the effect of making domestic price inflation less sensitive to the increase in aggregate demand.

A domestic firm also sets a sticky price in the local currency of the foreign economy. These prices are also determined according to Calvo-style contracts indexed to lagged foreign import price inflation, with the log-linearized first order condition associated with domestic 
producer $i^{\prime} s$ choice of a price to set in the foreign market given by:

$$
\begin{aligned}
\pi_{M t}^{*}-\pi_{M t-1}^{*}=\beta & \left(\pi_{M t+1 \mid t}^{*}-\pi_{M t}^{*}\right)+\kappa_{p} \Theta\left[\left(\zeta_{t}-m p l_{t}-q_{D t}\right)-\right. \\
& \left.\nu \mu\left(1-\omega_{C}^{*}\right) \eta_{c}\left(p_{M t}^{*}-p_{D t}^{*}\right)\right]
\end{aligned}
$$

where $q_{D t}=p_{D t}^{*}+e_{t}-p_{D t}^{*}$ is the real exchange rate in terms of domestic prices. This equation implies that foreign import prices (i.e., domestic export prices in units of the foreign currency) do not respond fully to changes in domestic marginal cost, or to changes in real exchange rates. In turn, the response of real trade flows is also muted. In contrast, in the workhorse model, changes in exchange rates have a relatively large effect on import prices and thus on real trade flows.

Figure 16 shows the effects of a technology shock for different degrees of openness in both the workhorse model with a constant elasticity of demand and the model with variable markups and pricing to market. For the model with variable markups, we set $\nu=3, \rho$ such that the aggregate elasticity $\eta_{c}$ equals its benchmark value of 1.5 , and $\gamma$ so that the steady state markup is 20 percent. Under our benchmark calibration, the variation in desired markups mutes the responsiveness of import and export prices to exchange rate changes and reduces the interest sensitivity of real trade flows. Comparing the top panels, there is a smaller difference in the response of output across the three calibrations in the pricing to market model, reflecting the lower sensitivity of aggregate demand to changes in interest rates. The response of output is also more persistent in the model, reflecting the higher degree of strategic complementarities associated with the variable desired markups.

The higher degree of strategic complementarity also implies less pass-through from marginal cost to domestic prices. Hence, there is a smaller response of inflation in the variable desired markups model than the workhorse model, regardless of the degree of openness. In addition, there are relatively large differences in the response of domestic inflation across the three calibrations in the variable markups model. Given that import prices rise, domestic firms have an incentive to raise their markups in response to weaker competition from imports, thus mitigating the fall in domestic price inflation. This effect is clearly more important in a highly open economy than in a relatively closed economy. 


\section{Conclusion}

In this paper, we used an open economy DSGE model to explore how trade openness affects the transmission of domestic shocks. Our results indicate that increased trade openness and international linkages are likely to have fairly modest implications for real activity and inflation, though more pronounced effects on the composition of expenditure and the wedge between consumer and domestic prices. Accordingly, to the extent that openness changes the behavior of the domestic economy, it seems plausible that the main effects would occur through an increased role of foreign shocks. 


\section{References}

Altonji, J. G. (1986). Intertemporal Substitution in Labor Supply: Evidence from Micro Data. Journal of Political Economy 94, 176-215.

Attanasio, O. and G. Weber (1995). Is Consumption Growth Consistent with Intertemporal Optimization? Evidence from the Consumer Expenditure Survey. Journal of Political Economy 103, 1121-1157.

Attanasio, O. and G. Weber (1997). Humps and Bumps in Lifetime Consumption. Journal of Business and Economics Statistics 17, 22-35.

Ball, L. (1994). What Determines the Sacrifice Ratio? In N. G. Mankiw (Ed.), Monetary Policy, pp. 155-182. University of Chicago Press.

Barsky, R., F. Juster, M. Kimball, and M. Shapiro (1997). Preferences Parameters and Behavioral Heterogeneity: An Experimental Approach in the Health and Retirement Study. Quarterly Journal of Economics 112, 537-579.

Benigno, G. and P. Benigno (2003). Price Stability in Open Economies. Review of Economic Studies 70, 743-764.

Bergin, P. R. and R. C. Feenstra (2001). Pricing-to-Market, Staggered Contracts, and Real Exchange Rate Persistence. Journal of International Economics 54, 333-59.

Betts, C. and M. B. Devereux (1996). The Exchange Rate in a Model of Pricing-to-Market. European Economic Review 40, 1007-21.

Card, D. (1994). Intertemporal Labor Supply: An Assessment. In C. Sims (Ed.), Frontiers of Econometrics.

Christiano, L. J., M. Eichenbaum, and C. L. Evans (2005). Nominal Rigidities and the Dynamic Effects of a Shock to Monetary Policy. Journal of Political Economy 113(1), $1-45$.

Clarida, R., J. Galí, and M. Gertler (1999). The Science of Monetary Policy. Journal of Economic Literature 37, 1661-1707.

Clarida, R., J. Galí, and M. Gertler (2001). Optimal Monetary Policy in Open vs Closed Economies. American Economic Review 91, 253-257.

Clarida, R., J. Galí, and M. Gertler (2002). A Simple Framework for International Monetary Policy Analysis. Journal of Monetary Economics 49, 879-904.

Corsetti, G. and P. Pesenti (2005). International Dimensions of Optimal Monetary Policy. Journal of Monetary Economics 52, 281-305.

Devereux, M. B. and C. Engel (2002). Exchange Rate Pass-Through, Exchange Rate Volatility, and Exchange Rate Disconnect. Journal of Monetary Economics 49, 91340 .

Devereux, M. B. and C. Engel (2003). Monetary Policy in the Open Economy Revisited: Price Setting and Exchange Rate Flexibility. Review of Economic Studies 70, 765-783. 
Dornbusch, R. (1983). Flexible Exchange Rates and Interdependence. IMF Staff Papers 30, 3-30.

Dornbusch, R. and S. Fischer (1984). The Open Economy: Implications for Monetary and Fiscal Policy. In R. J. Gordon (Ed.), The American Business Cycle: Continuity and Change, pp. 459-516. The University of Chicago Press.

Dotsey, M. and R. G. King (2005). Implications of State-Dependent Pricing for Dynamic Macroeconomic Models. Journal of Monetary Economics 52, 213-42.

Erceg, C., L. Guerrieri, and C. Gust (2006). SIGMA: A New Open Economy Model for Policy Analysis. Journal of International Central Banking 2(1), 1-50.

Erceg, C. J., D. W. Henderson, and A. T. Levin (2000). Optimal Monetary Policy with Staggered Wage and Price Contracts. Journal of Monetary Economics 46, 281-313.

Fleming, M. J. (1962). Domestic Financial Policies Under Fixed and Floating Exchange Rates. IMF Staff Papers 9(3), 369-379.

Galí, J. and T. Monacelli (2005). Monetary Policy and Exchange Rate Volatility in a Small Open Economy. Review of Economic Studies 72, 707-734.

Goldberg, P. K. and M. M. Knetter (1997). Goods Prices and Exchange Rates: What Have We Learned? Journal of Economic Literature 35, 1243-72.

Gust, C., S. Leduc, and R. J. Vigfusson (2006). Trade Integration, Competition, and the Decline in Exchange-Rate Pass-Through. International Finance Discussion Papers, Number 864, Board of Governors of the Federal Reserve System.

Gust, C. and N. Sheets (2006). The Adjustment of Global External Imbalances: Does Partial Exchange Rate Pass-Through to Trade Prices Matter? Federal Reserve Board, International Finance Discussion Papers, No. 850.

Hooper, P., K. Johnson, and J. Marquez (2000). Trade Elasticities for the G-7 Countries. Princeton Studies in International Economics.

Kimball, M. S. (1995). The Quantitative Analytics of the Neomonetarist Model. Journal of Money, Credit, and Banking 27, 1241-77.

Lane, P. R. (2001). The New Open Economy Macroeconomics: A Survey. Journal of International Economics 54, 235-66.

MacCurdy, T. (1986). An Empirical Model of Labor Supply in a Life-Cycle Setting. Journal of Political Economy 89, 1059-1085.

Marazzi, M., N. Sheets, and R. Vigfusson (2005). Exchange Rate Pass-Through to U.S. Import Prices: Some New Evidence. Federal Reserve Board, International Finance Discussion Papers, No. 833.

McCallum, B. T. and E. Nelson (1999). Nominal Income Targeting in an Open-Economy Optimizing Model. Journal of Monetary Economics 43(3), 553-579. 
Mulligan, C. B. (1998). Substitution Over Time: Another Look at Life-Cycle Labor Supply. In B. Bernanke and J. Rotemberg (Eds.), NBER Macroannual, Volume 13.

Mundell, R. A. (1962). The Appropriate Use of Monetary and Fiscal Policy for Internal and External Stability. IMF Staff Papers 9(1), 70-79.

Obstfeld, M. and K. Rogoff (1995). Exchange Rate Dynamics Redux. Journal of Political Economy 103, 624-60.

Pencavel, J. (1998). The Market Work Behavior and Wages of Women, 1975-94. Journal of Human Resources 33, 771-804.

Pencavel, J. (2002). A Cohort Analysis of the Association Between Work and Wages Among Men. The Journal of Human Resources 37(2), 251-274.

Ruhl, K. (2005). The Elasticity Puzzle in International Economics. University of Texas at Austin, mimeo.

Smets, F. and R. Wouters (2003). An Estimated Dynamic Stochastic General Equilibrium Model of the Euro Area. Journal of the European Economic Association 1(5), 11241175 .

Taylor, J. B. (1979). Estimation and Control of a Macroeconomic Model with Rational Expectations. Econometrica 47(5), 1267-1286.

Turnovsky, S. J. (1985). Domestic and Foreign Disturbances in an Optimizing Model of Exchange-Rate Determination. Journal of International Money and Finance 4(1), $151-71$.

Woodford, M. (2003). Interest and Prices. Princeton: Princeton University Press.

Woodford, M. (2007). Globalization and Monetary Control. NBER Working Paper Number 13329. 


\section{Appendix}

This appendix describes how the presence of imported materials affect the overall elasticity of demand with respect to the real interest rate.

Proceeding as in Section 3, simple algebraic manipulations allow us to obtain a relationship among domestic output, the terms of trade, and domestic and foreign shocks. A log-linear approximation to the aggregate resource constraint can be written as follows:

$$
y_{D t}=\left(1-\omega_{L}\right)\left(1-g_{y}\right)\left\{\left(1-\omega_{c}\right) c_{D t}+\omega_{c} m_{C t}^{*}\right\}+\omega_{L} m_{Y t}^{*}+\left(1-\omega_{L}\right) g_{y} g_{t}
$$

Following the steps used in Section 3, the term in brackets $\left\{\left(1-\omega_{c}\right) c_{D t}+\omega_{c} m_{C t}^{*}\right\}$ can be written in terms of foreign consumption and terms of trade (i.e. $\left.\left(\sigma^{o p e n} \tau_{t}-c_{D t}^{*}\right)\left(1-g_{y}\right)\left(1-\omega_{L}\right)\right)$. The task then is to find an expression that relates $m_{Y t}^{*}$ to foreign variables and the terms of trade. Import demand of materials in the foreign economy is given by: ${ }^{28}$

$$
m_{Y t}^{*}=y_{D t}^{*}+\left(1-\omega_{L}^{*}\right)\left(1-\omega_{c}^{*}\right) \eta_{L}\left[\xi_{t}^{*}-z_{t}^{*}+\tau_{t}\right]
$$

Assuming that wages are flexible, we can use the MRS in the foreign economy to express the foreign product real wage real wage in terms of foreign variables and the terms of trade. Thus, domestic demand can be written in a more compact way as follows:

$$
\begin{gathered}
y_{D t}=\left(\sigma^{\text {open }} \tau_{t}-c_{D t}^{*}\right)\left(1-g_{y}\right)\left(1-\omega_{L}\right)+\omega_{L}\left(1-\omega_{L}^{*}\right)\left(1-\omega_{c}^{*}\right) \eta_{L} \tau_{t} \\
+\left(1-\omega_{L}\right) g_{y} g_{t}+\omega_{L} f_{t}^{*},
\end{gathered}
$$

where $f_{t}^{*}$ represents a combination of foreign variables. Relative to the benchmark model, the previous expression makes clear that fluctuations in imported materials introduce an additional effect of the terms of trade on domestic output, whose intensity depends upon the share of imported materials on gross production $\left(\omega_{L}\right)$, the share of imports of the foreign economy $\left(\omega_{c}^{*}\right)$ and the elasticity of substitution of materials $\left(\eta_{L}\right)$ and value added in gross production. The previous expression can be rearranged as follows:

$$
y_{D t}=\left(\sigma_{M}^{o p e n} \tau_{t}-\left(1-\omega_{L}\right) c_{D t}^{*}\right)\left(1-g_{y}\right)+\left(1-\omega_{L}\right) g_{y} g_{t}+\omega_{L} f_{t}^{*},
$$

where $\sigma_{M}^{\text {open }}$ is given by:

$$
\sigma_{M}^{\text {open }}=\sigma^{\text {open }}\left(1-\omega_{L}\right)+\omega_{L} \frac{\left(1-\omega_{L}^{*}\right)\left(1-\omega_{c}^{*}\right) \eta_{L}}{\left(1-g_{y}\right)} .
$$

Assuming that the home economy is sufficiently small, we can rewrite this expression as:

$$
\sigma_{M}^{\text {open }}=\sigma^{\text {open }}\left(1-\omega_{L}\right)+\omega_{L} \frac{\eta_{L}}{\left(1-g_{y}\right)}
$$

If $\omega_{L}=0$, this expression is the same as the one for the workhorse model.

\footnotetext{
${ }^{28}$ For convenience, we assume that the value added function is linear in labor $(\alpha=0)$.
} 
Table 1: Slope of Reduced Form MRS Schedule for Alternative Calibrations Benchmark Frisch Elasticity $\left(\chi^{-1}=0.2\right)$

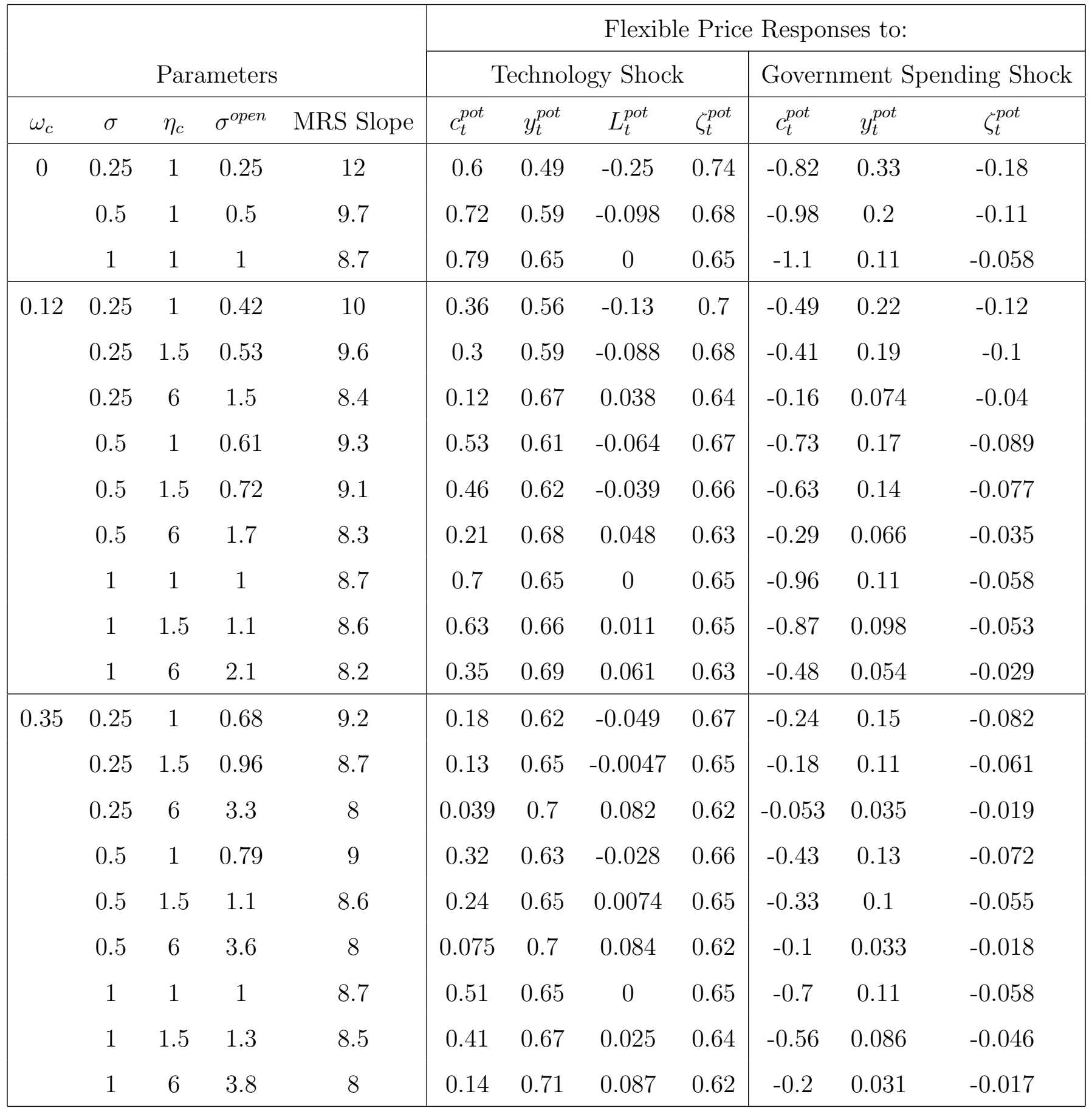


Table 2: Slope of Reduced Form MRS Schedule for Alternative Calibrations Higher Frisch Elasticity $\left(\chi^{-1}=1\right)$

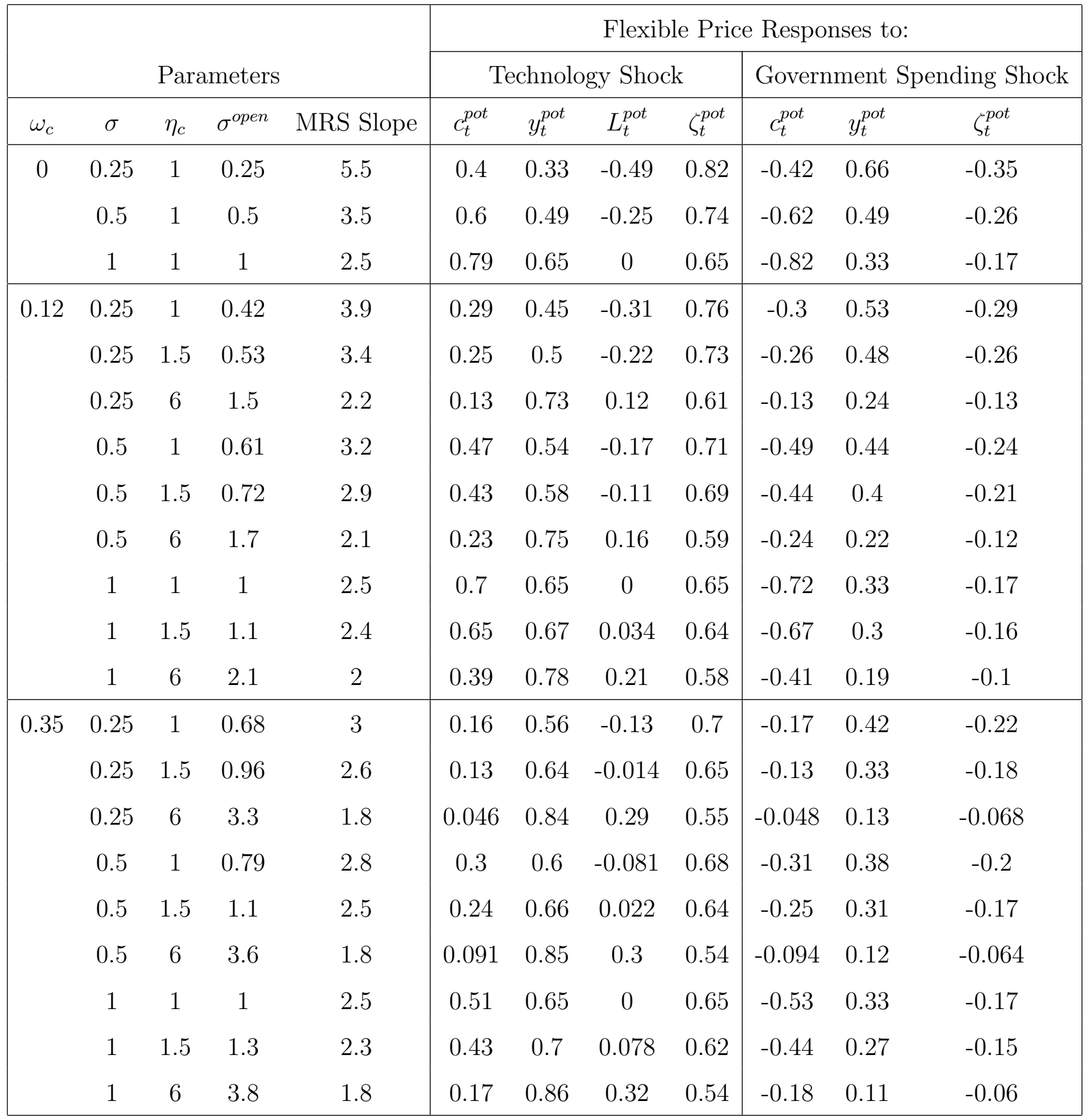


Figure 1: Permanent Reduction in the Inflation Target in SIGMA (Deviation from Steady State)
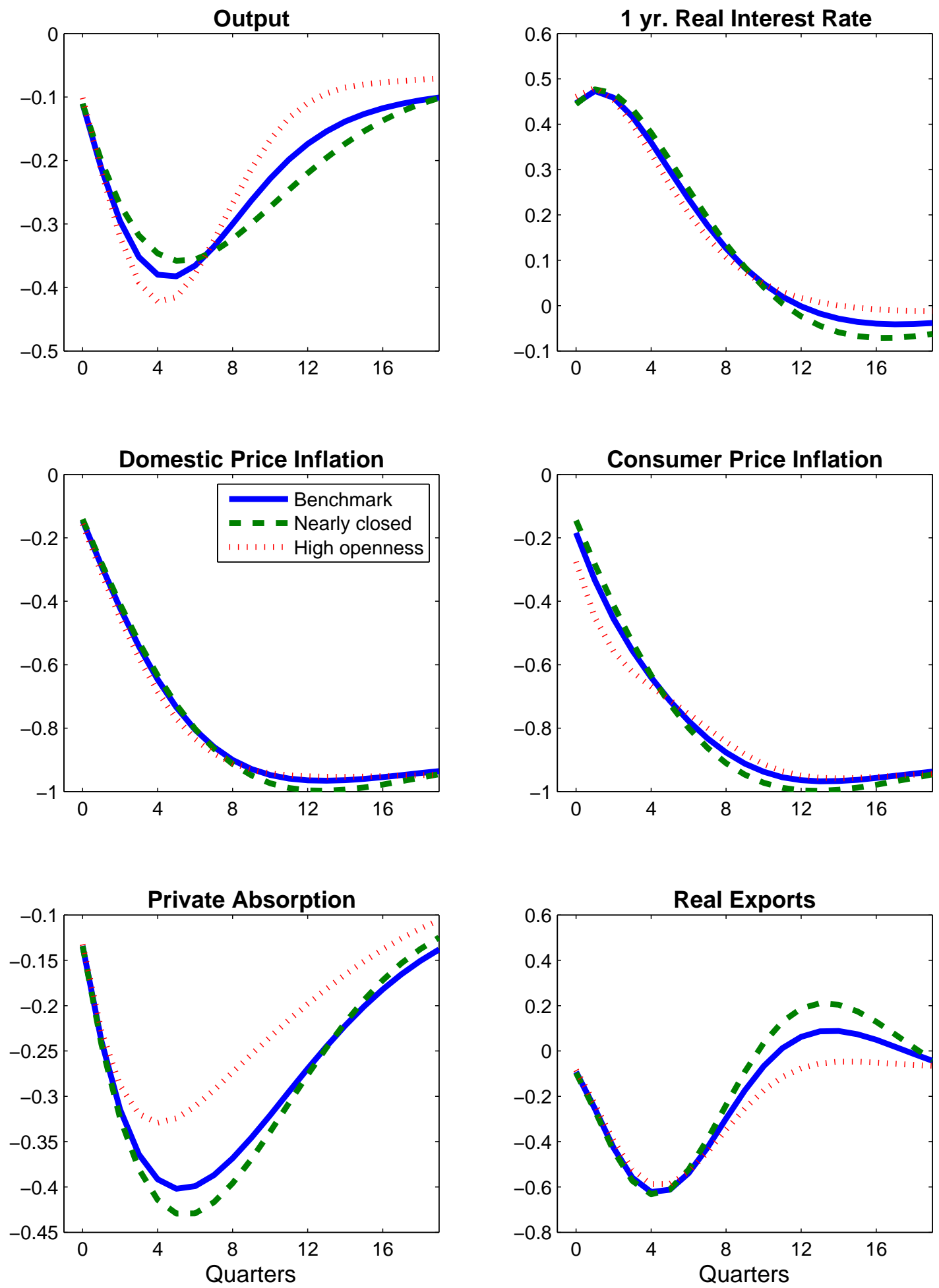
Figure 2: Disinflation Episodes in U.S., Canada, and the U.K.
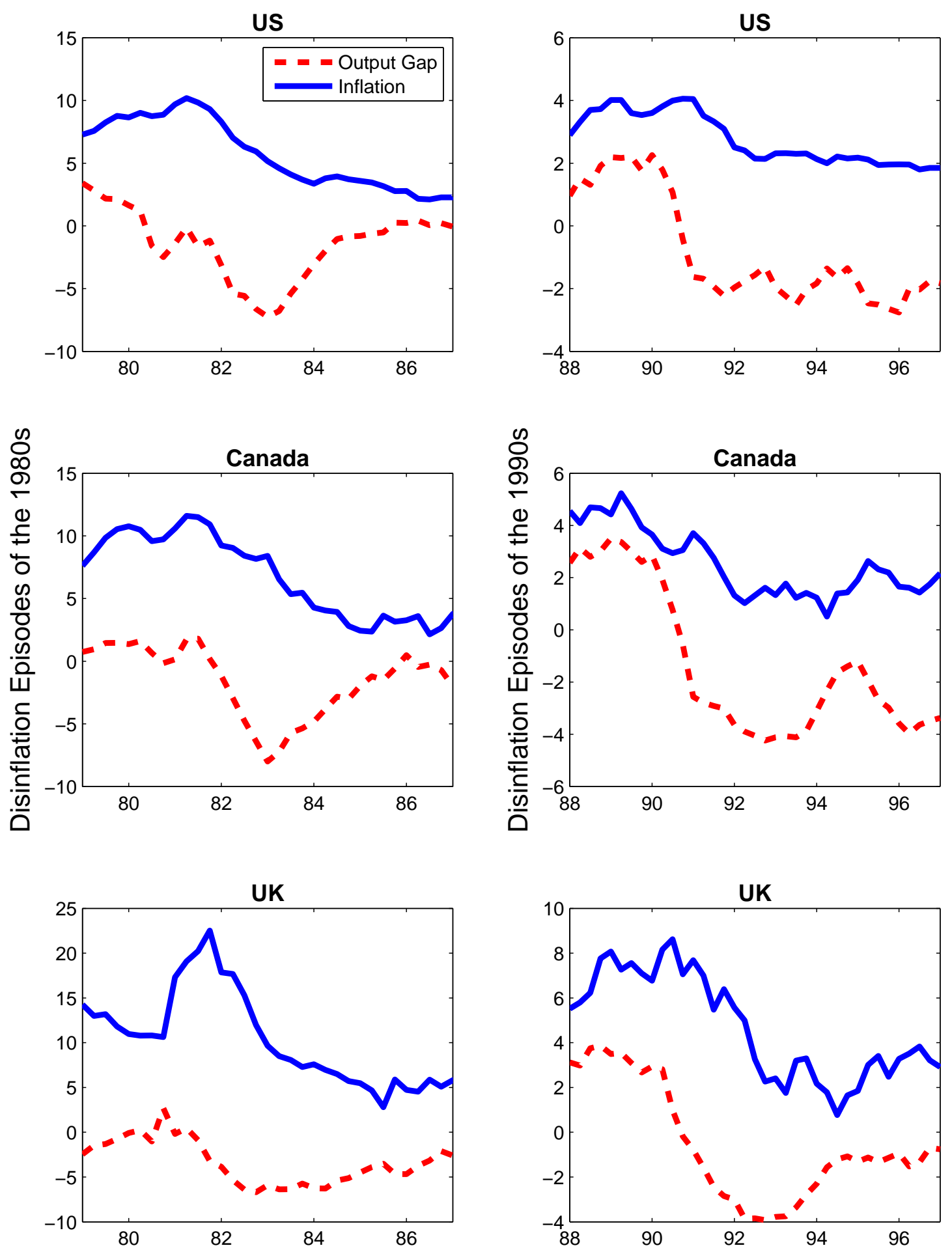
Figure 3: Increase in Government Spending in SIGMA

(Deviation from Steady State)
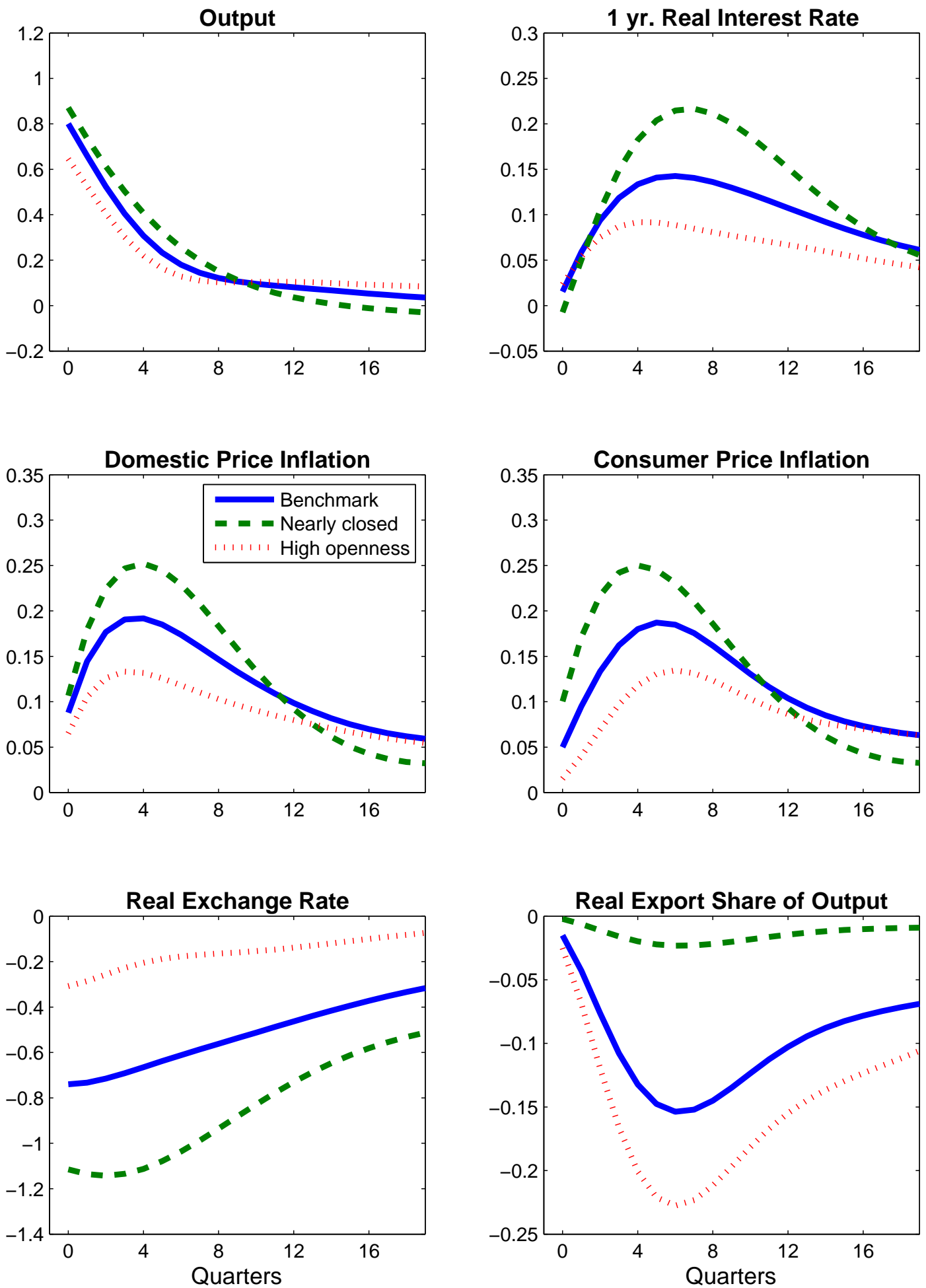
Figure 4: Increase in Technology in SIGMA

(Deviation from Steady State)
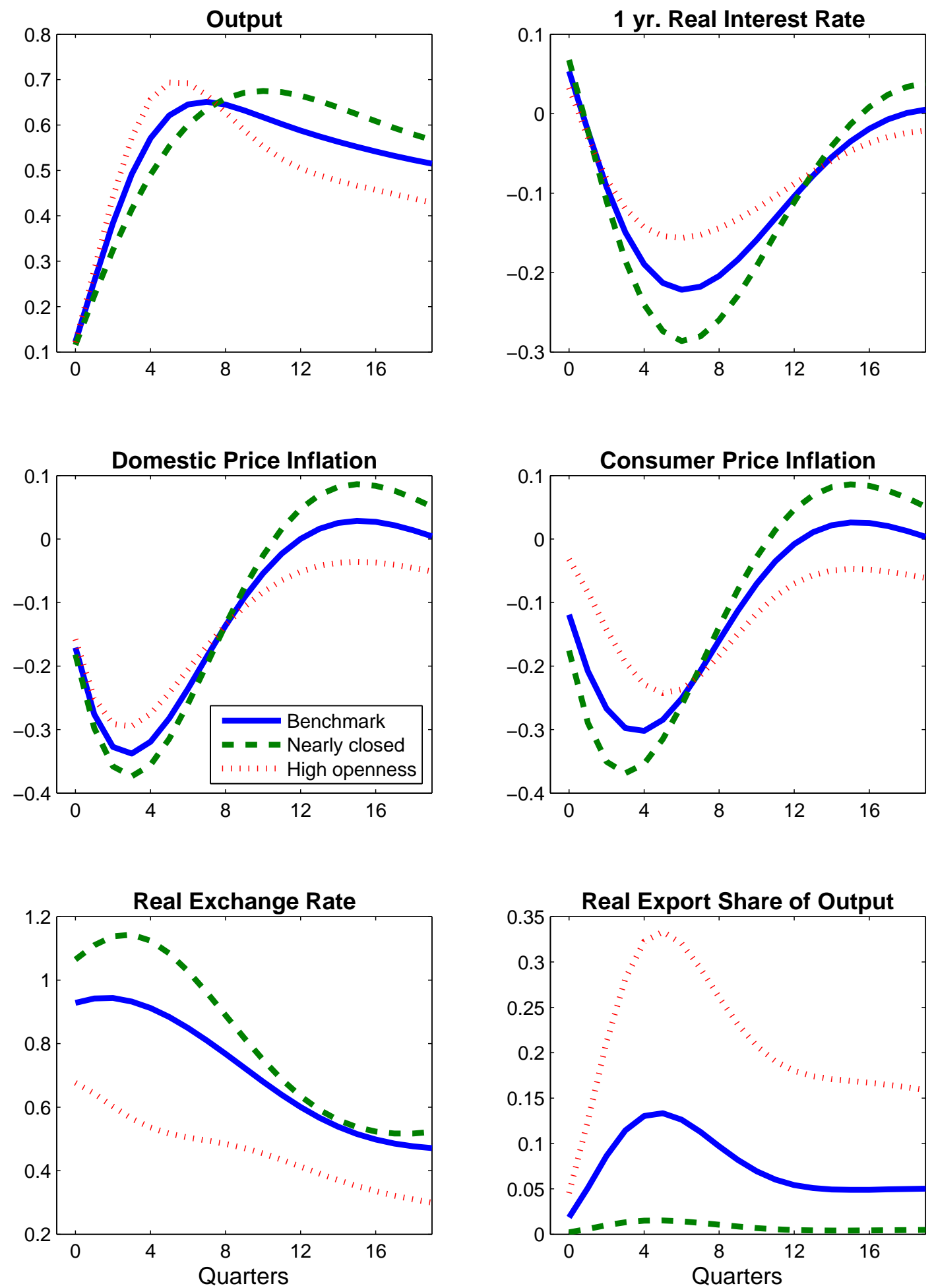
Figure 5: Rise in Technology: Closed vs. Open

Labor Market Equilibrium under Flexible Prices and Wages
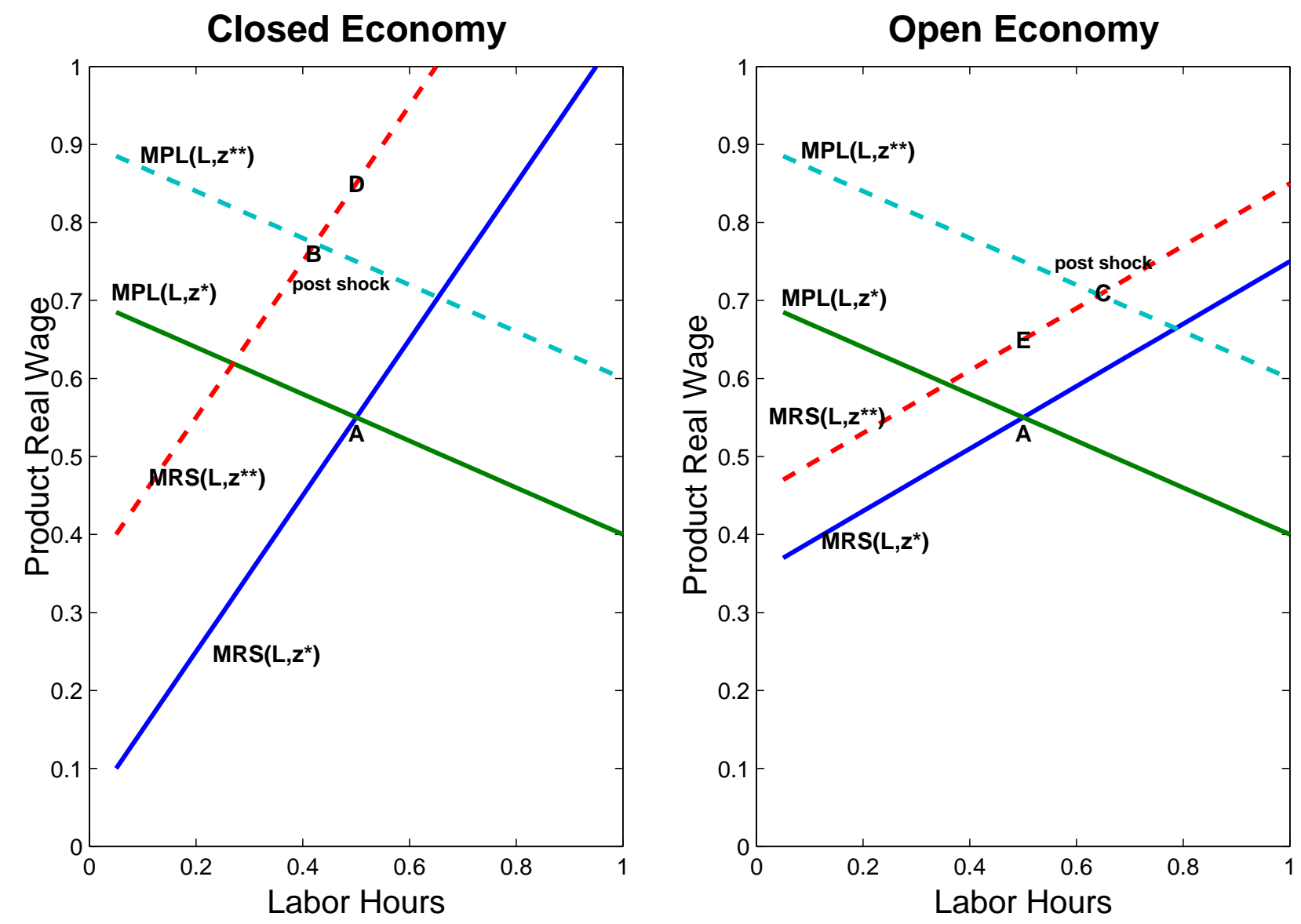
Figure 6: Increase in Inflation Target in Workhorse Model

(Deviation from Steady State)
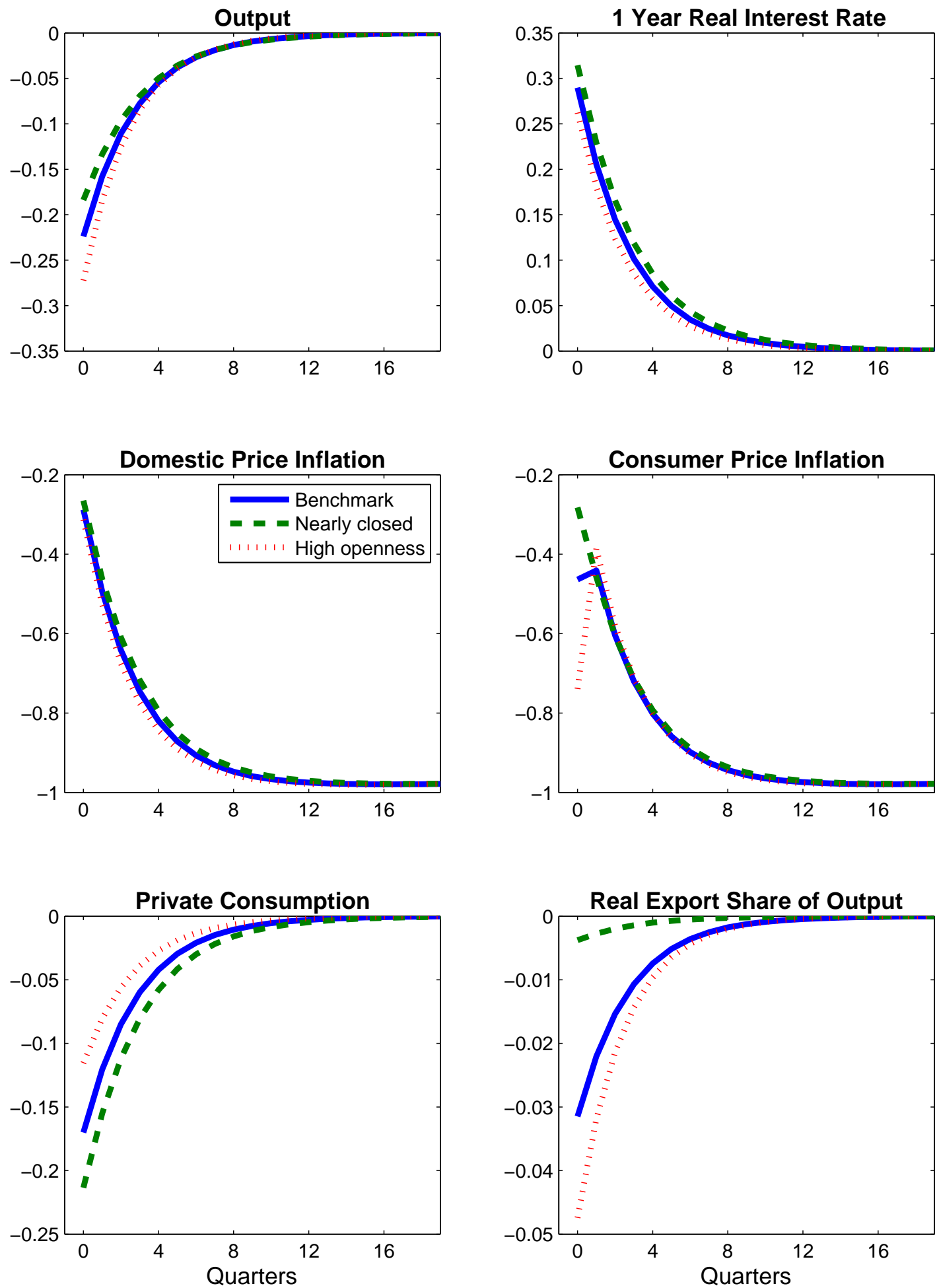
Figure 7: Increase in Government Spending in Workhorse Model

(Deviation from Steady State)
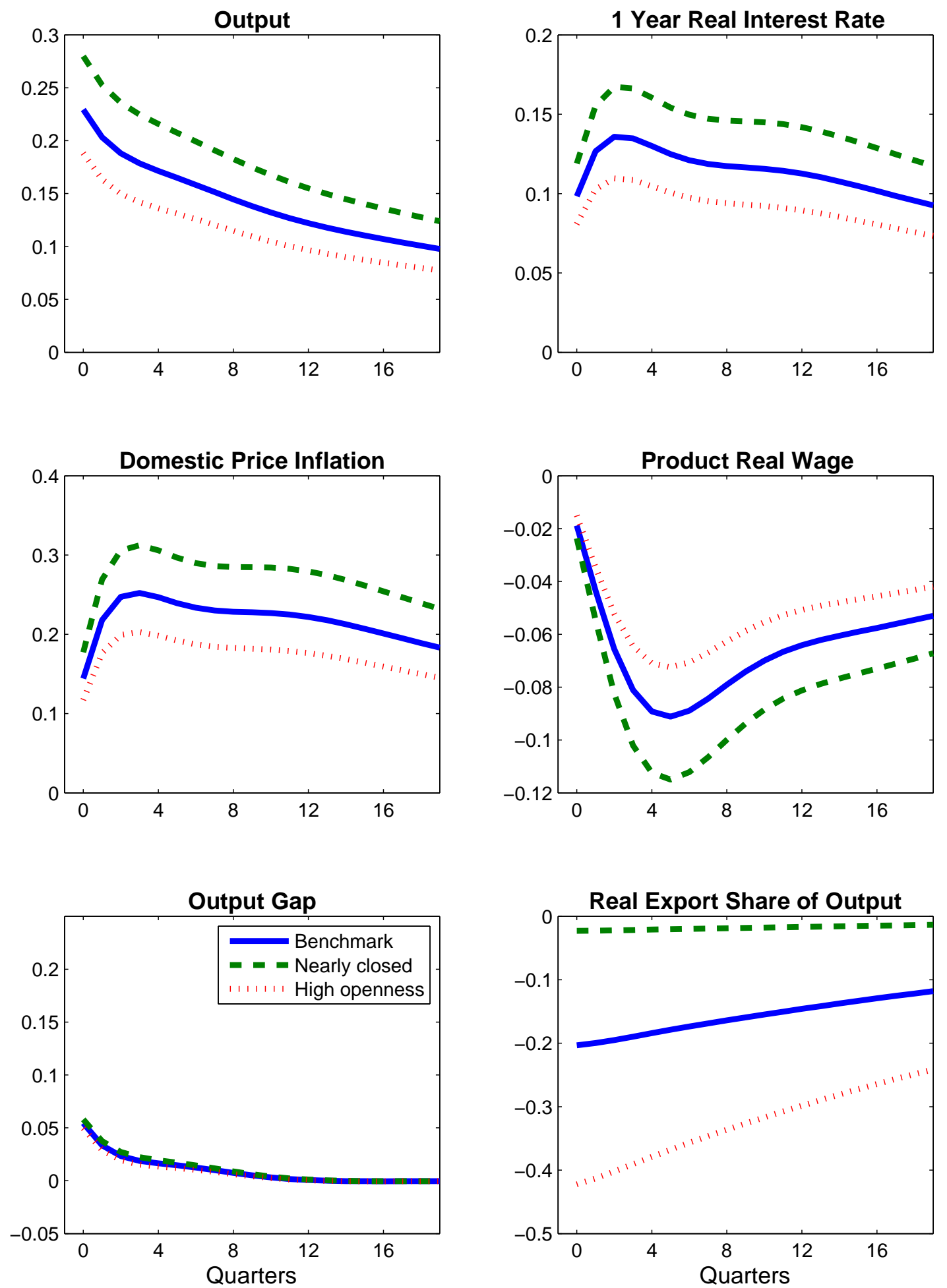
Figure 8: Increase in Technology in Workhorse Model

(Deviation from Steady State)
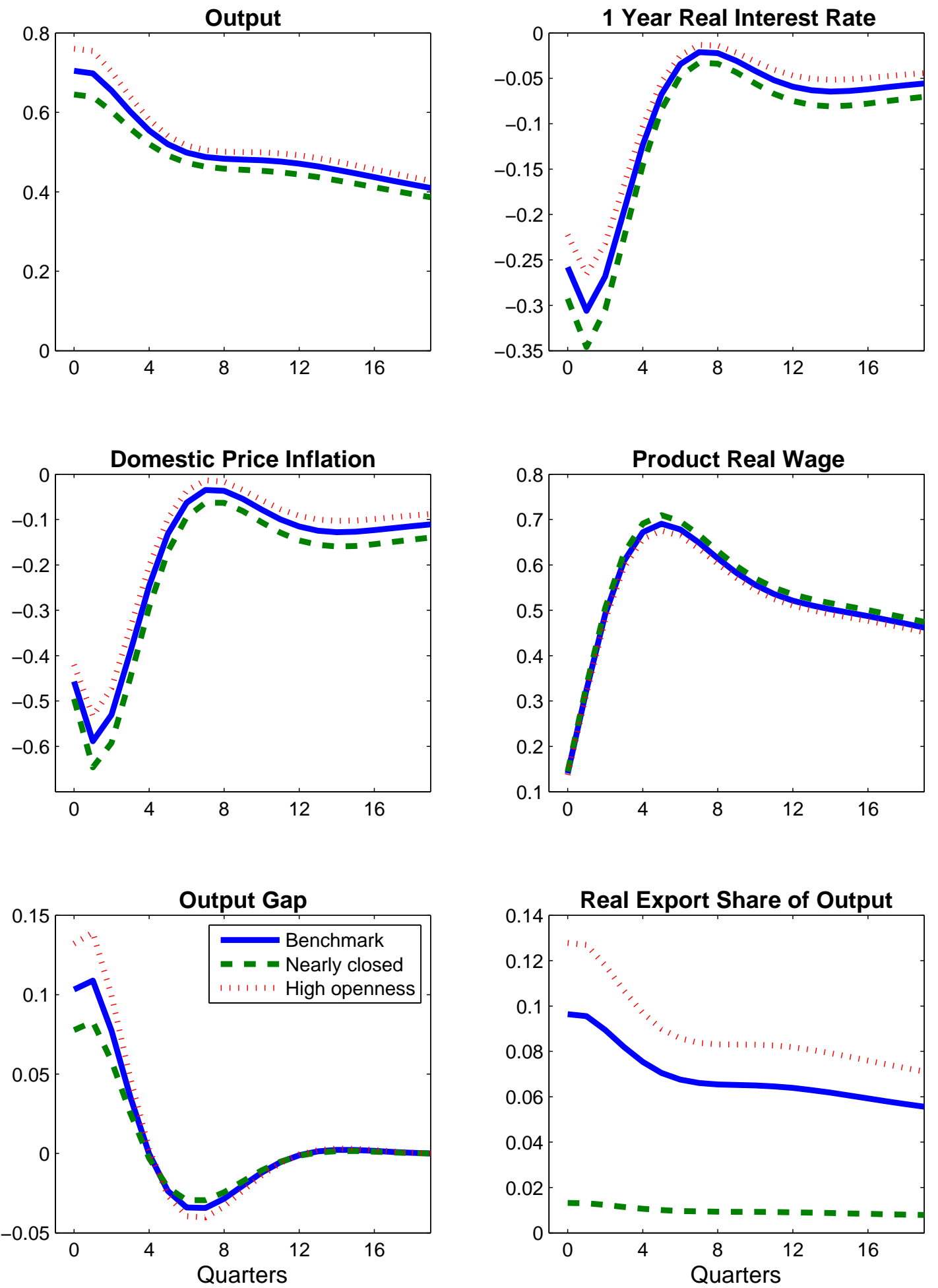
Figure 9: Increase in Technology in Workhorse Model

(Alternative Calibration: $\eta=6$ and $\chi^{-1}=1$ )
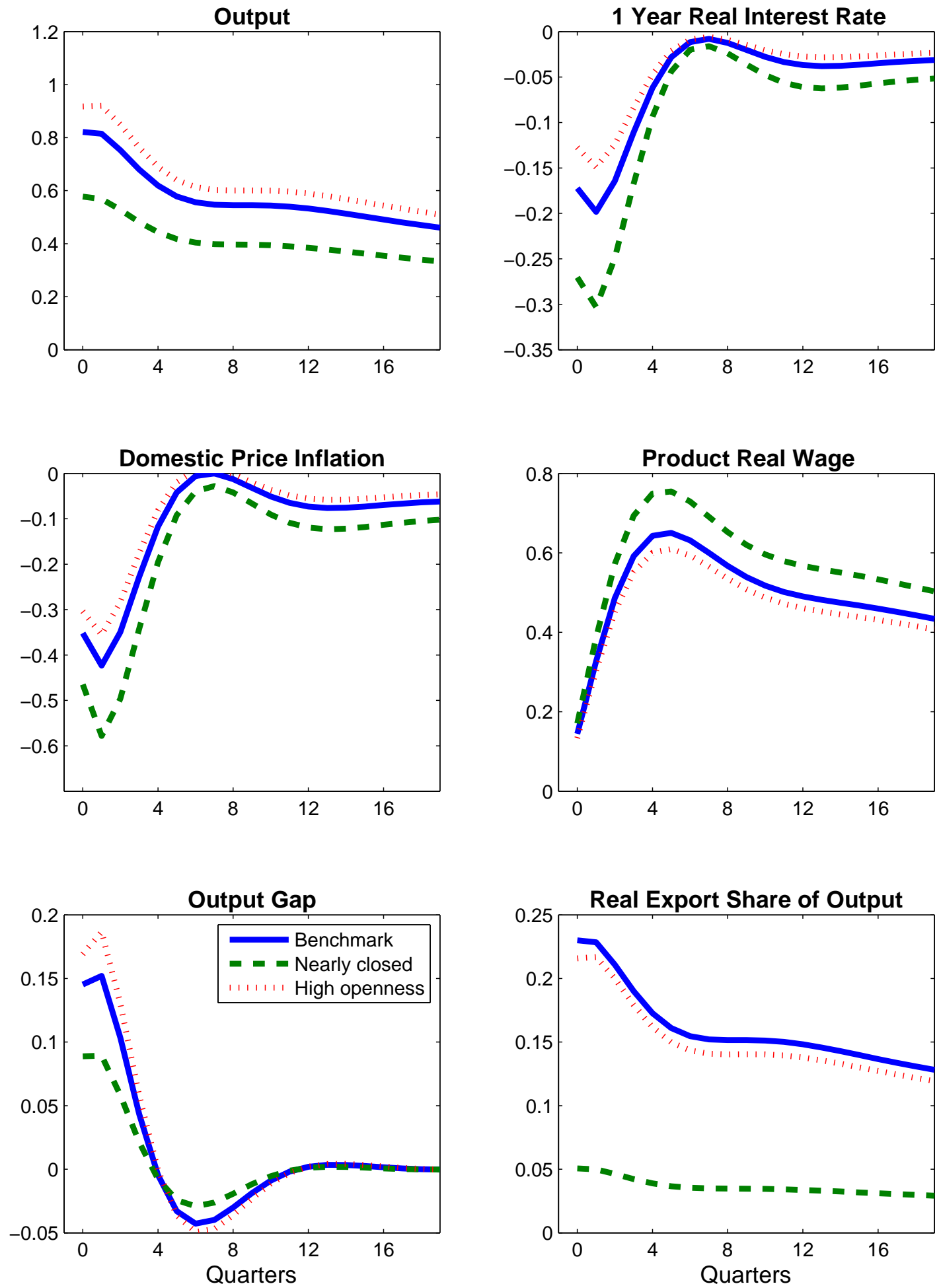
Figure 10: Policy Tradeoff Frontier for Technology Shock

Benchmark Calibration
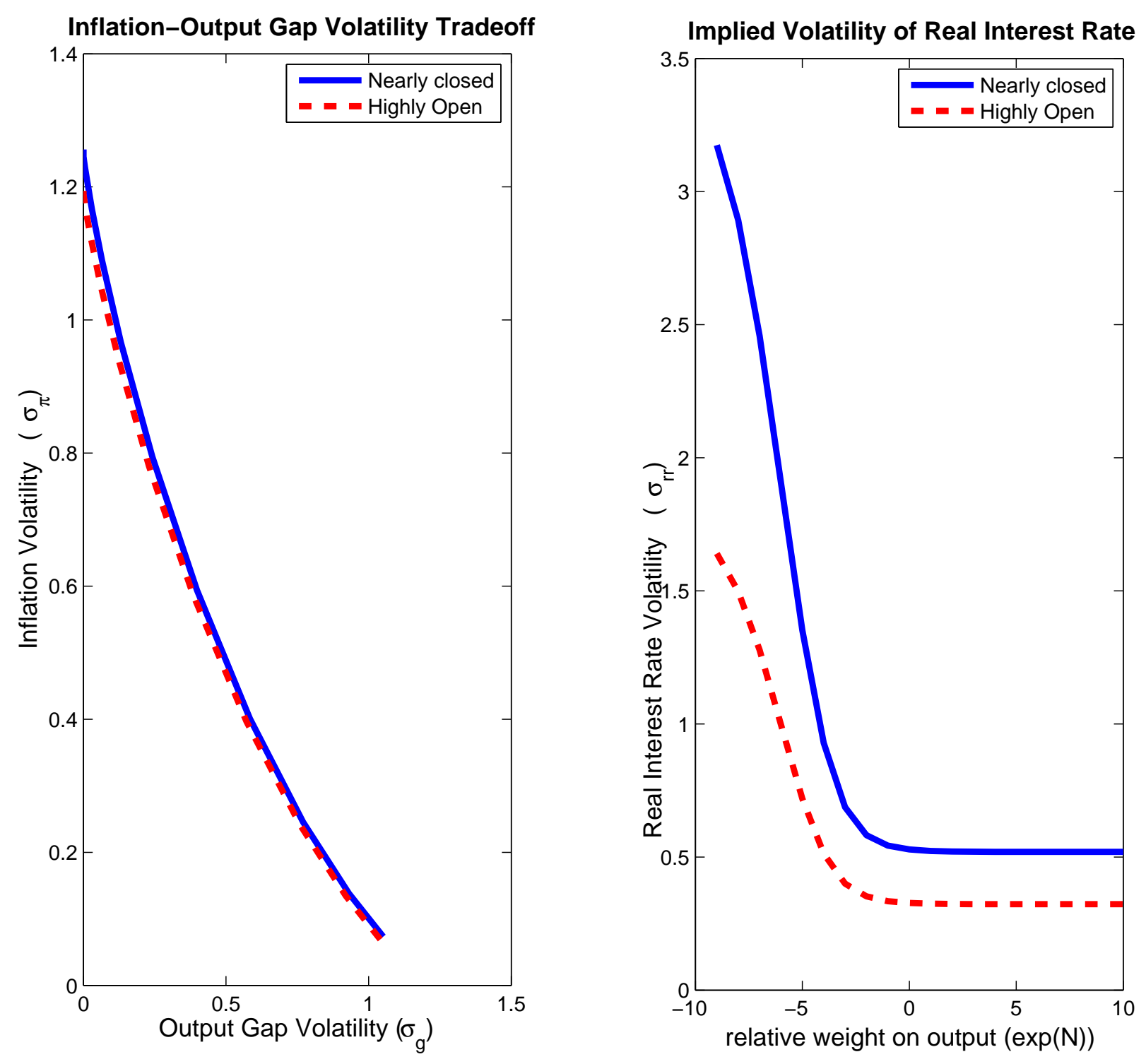
Figure 11: Policy Tradeoff Frontier for Technology Shock Alternative Calibrations

Alternative 1: Flatter MRS than benchmark $\left(\chi=2, \eta_{c}=3, \alpha=.35\right)$

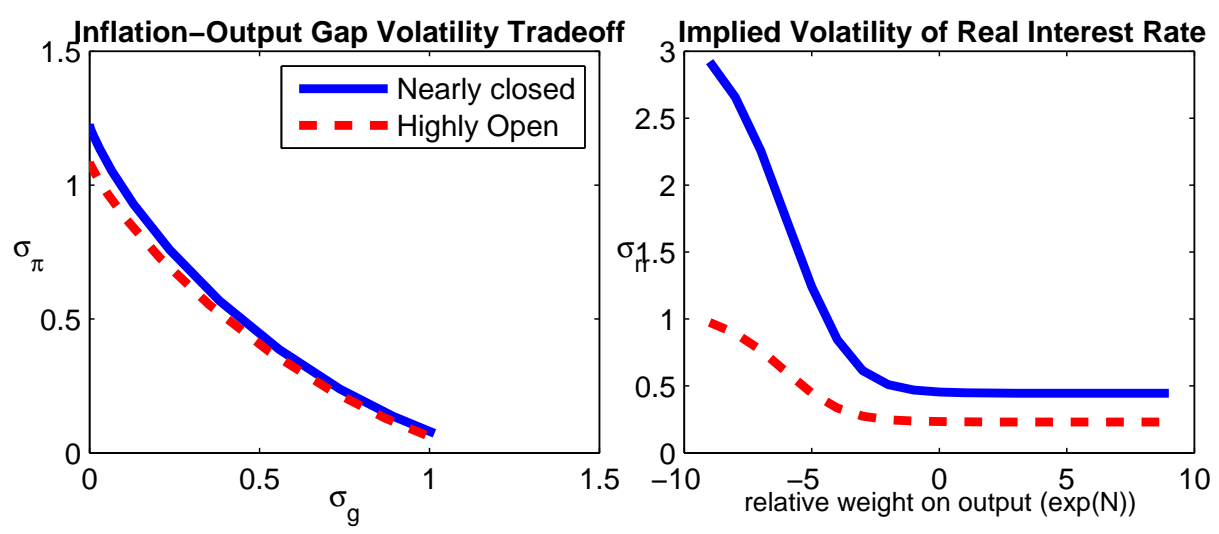

Alternative 2: Very Flat MRS $\alpha=.05, \eta_{c}=6, \alpha=.35$ )

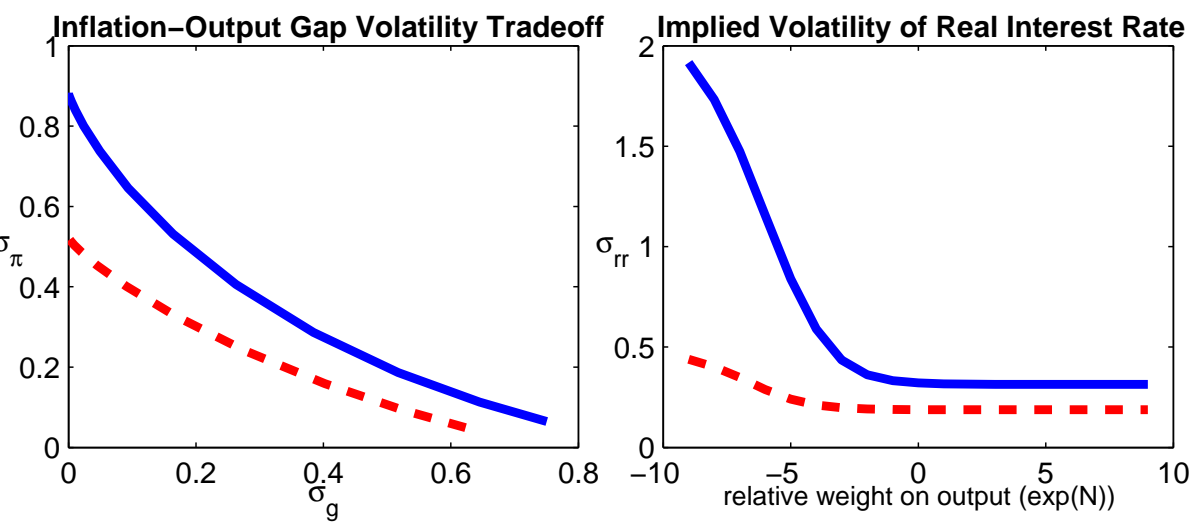

Alternative 3: Very Flat MRS AND MPL $\left.\alpha=.05, \eta_{c}=6, \alpha=.05\right)$

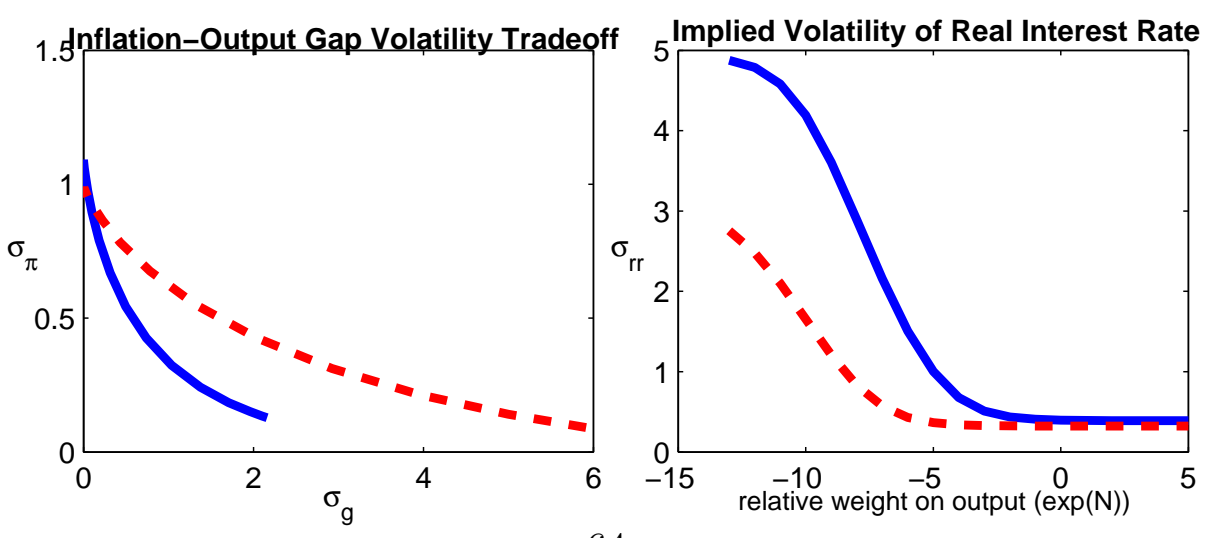


Figure 12: Persistent Increase in Technology: Complete vs. Incomplete Markets

Complete Markets
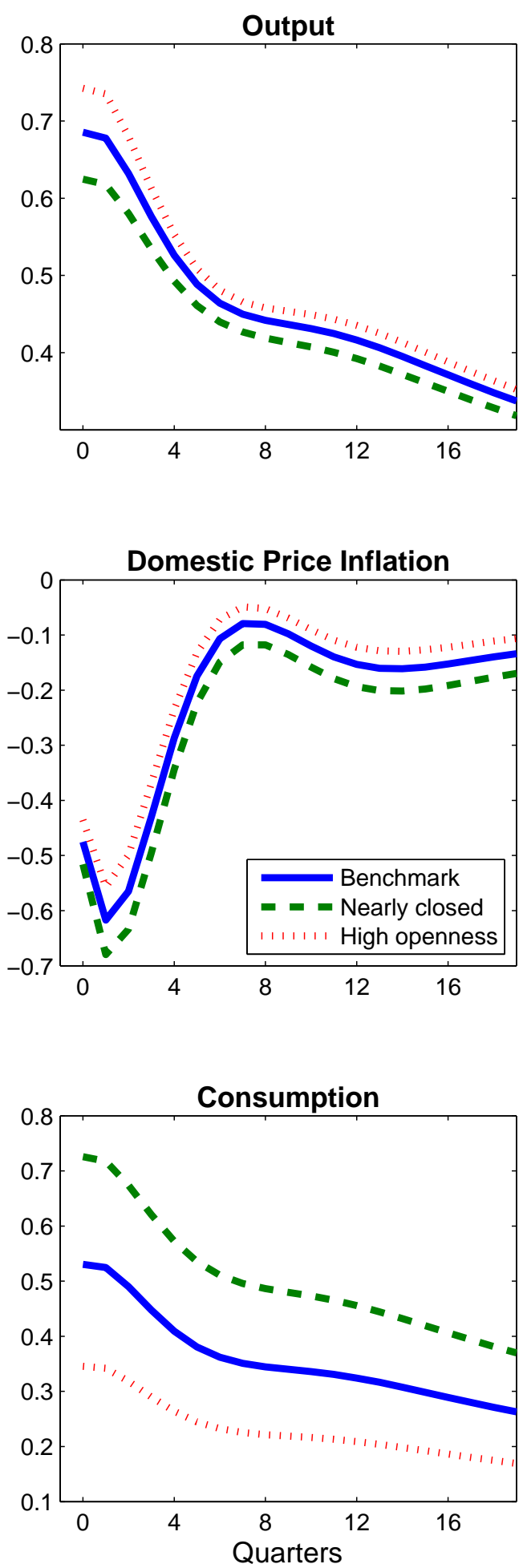

Incomplete Markets
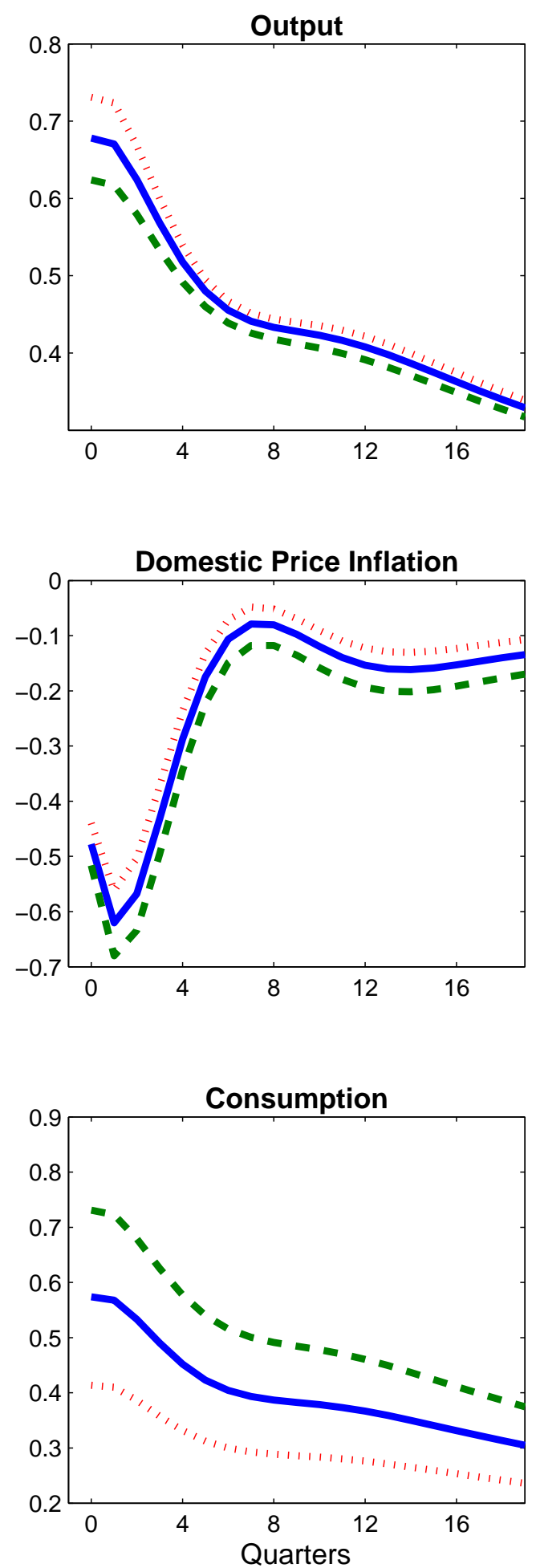
Figure 13: The Effect on Output of a More Transitory Increase in Technology (Alternative Calibrations of Incomplete Markets Model)
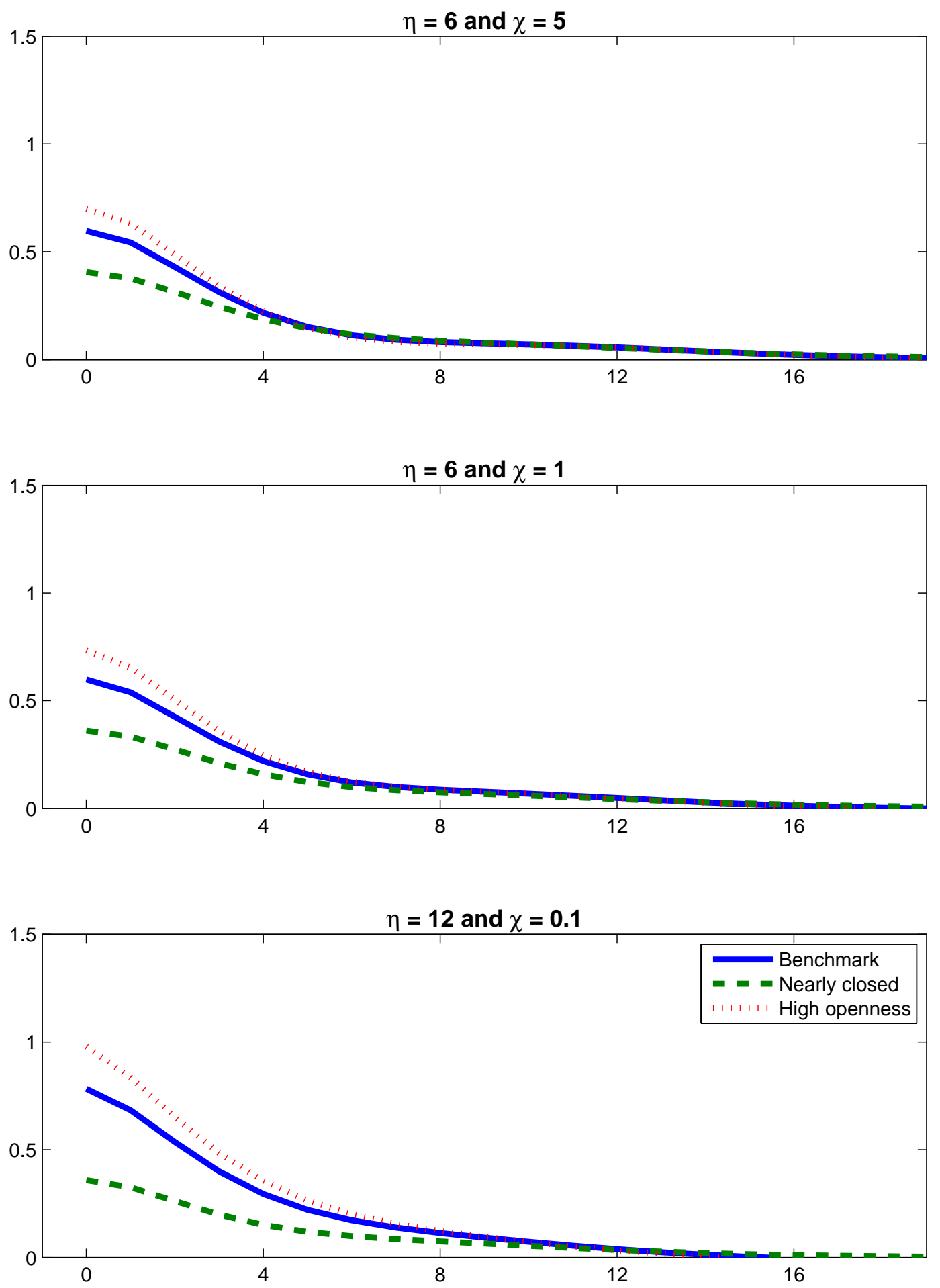
Figure 14: Reduction in Inflation Target in Endogenous Investment Model

Alternative $1: \eta_{c}=1.5$ and $\phi_{1}=0.2$
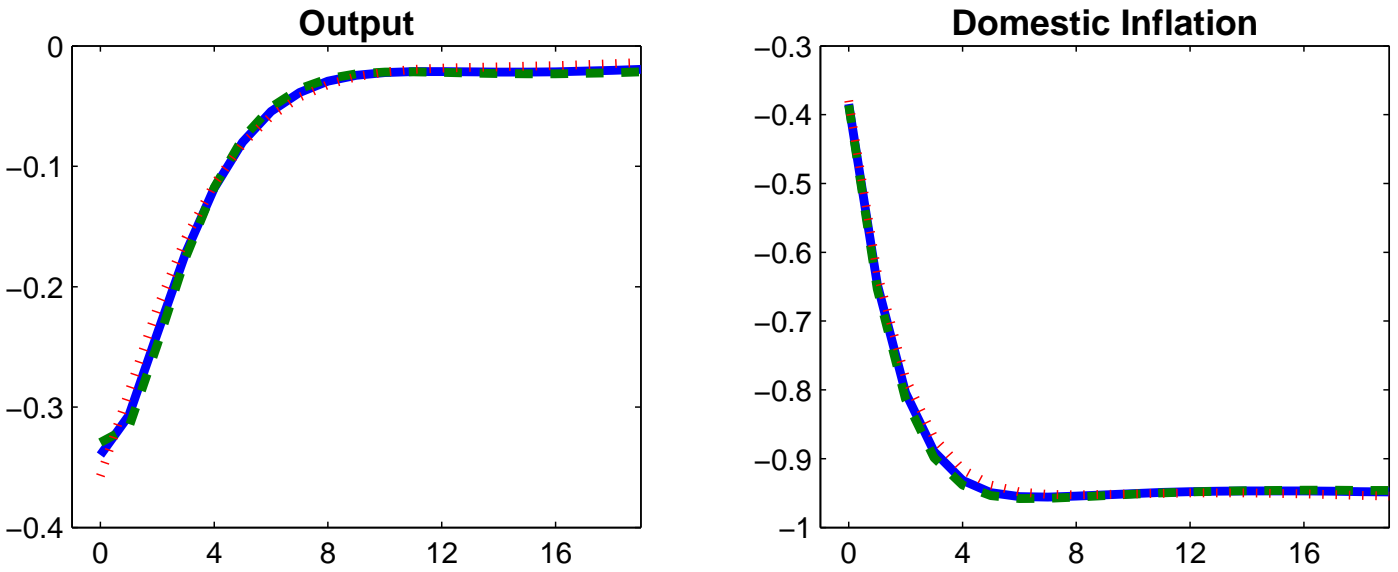

Alternative 2: $\eta_{c}=6$ and $\phi_{1}=0.2$
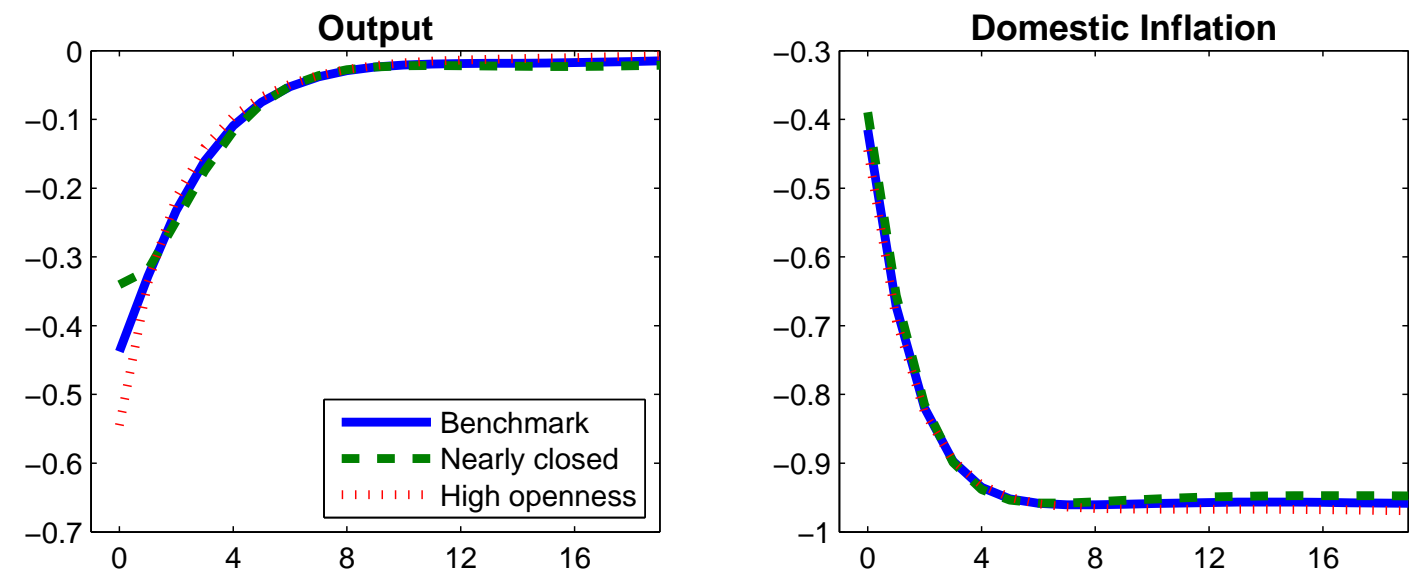

Alternative 3: $\eta_{c}=1.5$ and $\phi_{1}=0.01$
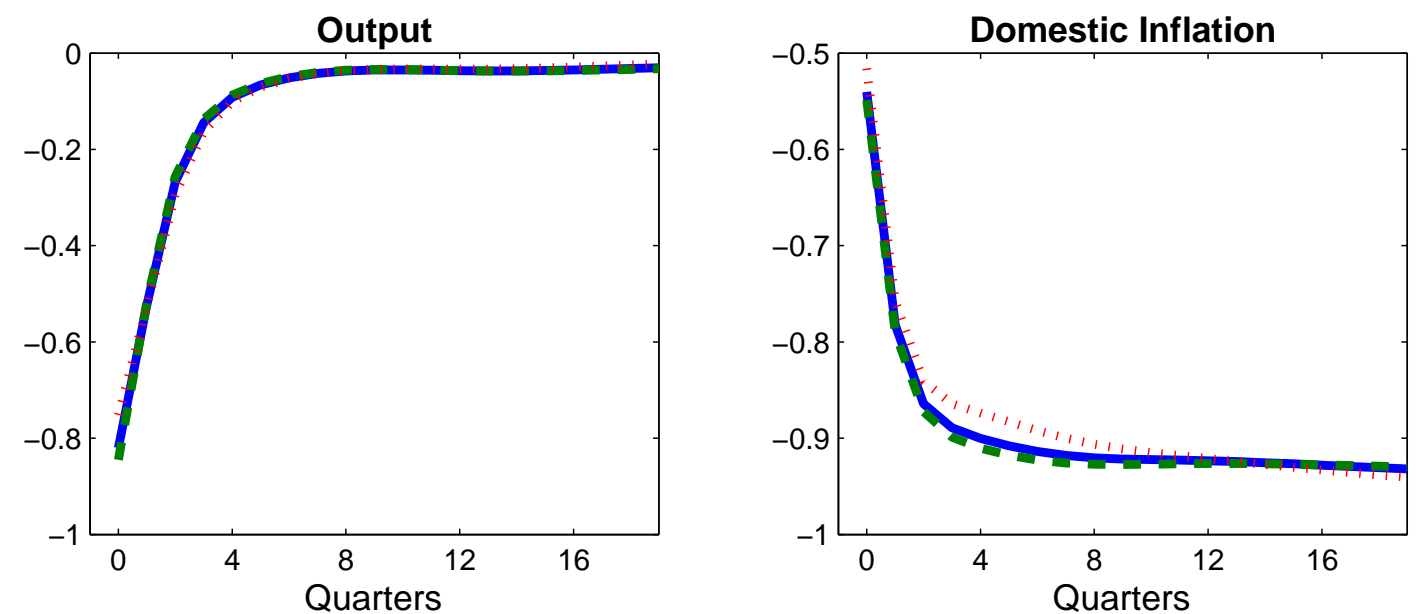
Figure 15: Increase in Technology: Workhorse Model vs. Imported Materials Model

Benchmark: No Imported Materials
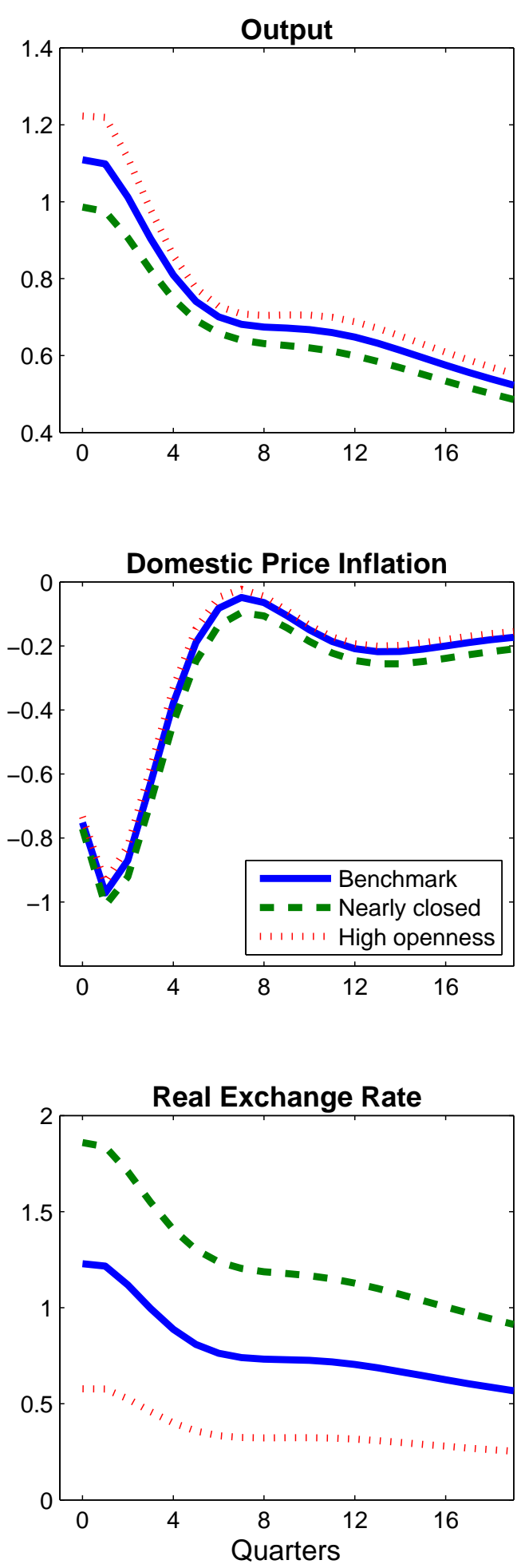

Imported Materials
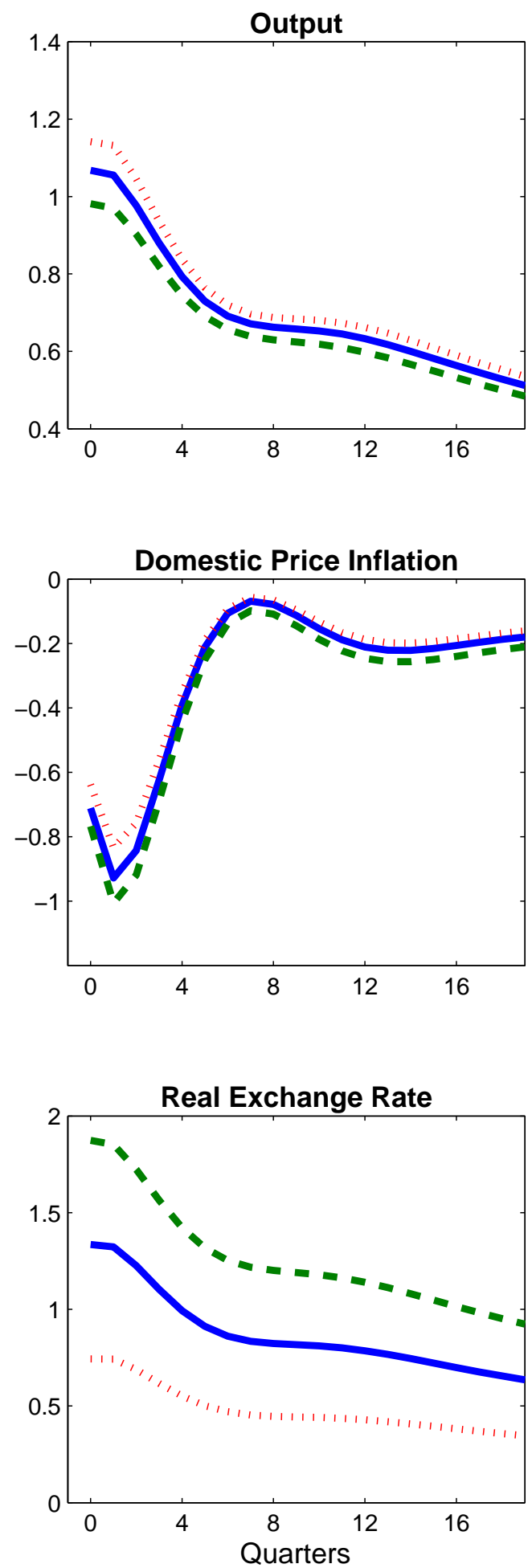
Figure 16: Increase in Technology: Workhorse Model vs. Variable Desired Markups Model

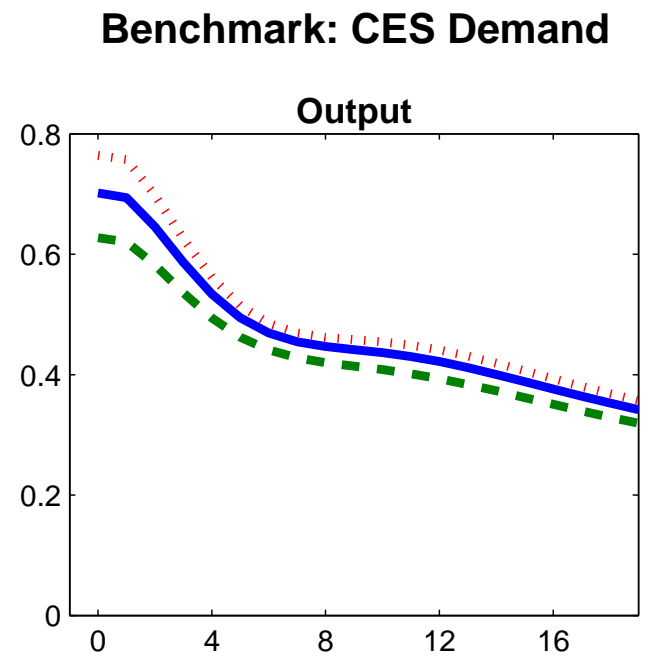

\section{Variable Elasticity of Demand}
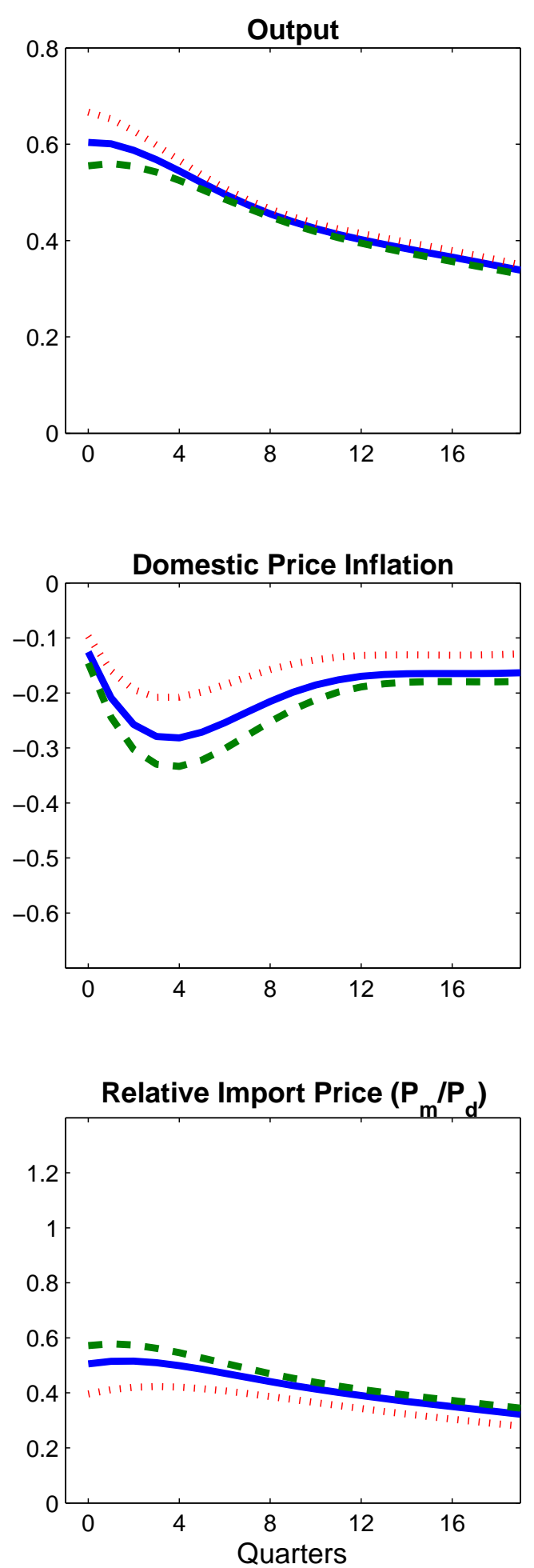